\title{
Algorithmic Opportunity Structures and the Dynamics of Online Activism: Far-Right Mobilization on Facebook
}

\author{
Thomas R. Davidson* \\ Department of Sociology \\ Rutgers University
}

This paper introduces the concept of algorithmic opportunity structures to explore how the efficacy of online activism is contingent on the interaction between algorithms, activists, and audiences. In particular, I examine how far-right actors have gamed ranking and recommendation algorithms by producing content designed to generate high engagement rates. This tactic attracts algorithmic amplification, increasing their visibility and reach on social media. I consider the case of Britain First, a far-right, anti-Muslim movement that used Facebook to rapidly build the largest audience of any political organization in the United Kingdom. I use digital trace data, time series analysis, and topic modeling to study Britain First's activity, recruitment, and support on Facebook. I identify dynamic equilibria indicative of algorithmically-mediated feedback loops, highlighting how variation in these processes is largely a function of user engagement. The content of the group's posts and exogenous events, including elections and terrorist attacks, are also associated with short-term fluctuations in online mobilization. The results suggest that Britain First's success is attributable to its exploitation of Facebook's algorithms, demonstrating how technological assemblages designed and controlled by corporations can structure political competition and moderate opportunities for activism.

\author{
UNDER REVIEW \\ Replication materials will be shared upon publication. \\ Please contact me via email you have any questions or comments.
}

\footnotetext{
*Acknowledgments: An earlier version of this work was presented at the 2019 American Sociological Association Annual Meeting. I thank Mabel Berezin, Peter Enns, Filiz Garip, Sang Lee, Michael Macy, Paul McLean, Barum Park, Emily Parker, and Hana Shepherd for their valuable comments and suggestions. Contact information: Thomas R. Davidson, 109 Davison Hall, 26 Nichol Avenue, Rutgers University, New Brunswick, NJ 08901. Email: thomas.davidson@rutgers.edu.
} 
Social media platforms have become a central feature of the political landscape, used to consume news, discuss politics, and engage in activism. Political parties, social movements, and advocacy groups employ social media to campaign, fundraise, and mobilize. Over the past decade, public perceptions of social media have radically shifted. Platforms once lauded as the bedfellows of democratic, progressive movements like the Arab Spring, the Occupy Movement, and the Indignados (Castells 2012; Gerbaudo 2012) are now vilified for undermining democracy across the globe, contributing to events including the Brexit referendum, the election of Donald Trump, and the growth of the "Alt-Right" (Tucker et al. 2017). While social media alone cannot explain these transformations, some scholars have contended that right-wing actors have been particularly effective at using these digital tools, identifying an "elective affinity" between social media and populism (Gerbaudo 2018) and arguing that digital activism tends to favor conservatives (Schradie 2019).

Most existing sociological work on social media and social movements considers these technologies as catalysts for conventional diffusion processes. From this perspective, social media has enabled quantitative shifts in the diffusion of collective action, allowing information to spread faster and more widely, while leaving the activism itself qualitatively unchanged (Earl 2010). Social media allow activists to quickly and cheaply reach large audiences, leading the work of online activism to be characterized as "connective action" (Bennett and Segerberg 2012). Unlike conventional diffusion processes, however, the diffusion of information on contemporary social media platforms is mediated by algorithms used to rank and recommend content. Facebook began ranking content shown to users by popularity in 2009 and Twitter phased out its reversechronological timeline in favor of a ranked feed in 2016. This has fundamentally changed the online information landscape with clear implications for contemporary politics. There has been 
intense scholarly debate regarding the extent to which these developments have created "filter bubbles" (Pariser 2011) and "echo chambers" (e.g. Cinelli et al. 2021) that exacerbate political polarization, but the implications for collective action have largely been overlooked (c.f. Tufekci 2018; Schradie 2019).

I draw upon social movement studies and communication scholarship to develop the concept of algorithmic opportunity structures to explain how the algorithms deployed on contemporary social media platforms alter the possibilities for collective action. Social movements scholars emphasize how exogenous factors such as institutional configurations and historical precedents constitute political opportunity structures, which enhance or inhibit mobilization efforts, influence strategic choices, and condition the potential impact of activism (McAdam [1982]2010; Kitschelt 1986; Meyer and Minkoff 2004). Like institutions, algorithms moderate the impact of activism on the political environment, potentially favoring some strategies and tactics over others (Napoli 2014). Algorithms can also play a similar role to the media by determining which discourse and ideas are rendered visible and legitimate (Koopmans and Olzak 2004). Unlike political institutions and the media, however, the algorithms used by social media platforms are complex technological assemblages controlled by private corporations, without significant regulation. To understand how political actors can use algorithms to their advantage, I draw upon the concept of affordances to describe how actors interact with and make use of different features of technologies (Gibson 2014; boyd 2010; Nagy and Neff 2015). From this perspective, algorithms must be considered as inherently relational (Emirbayer 1997): algorithmic opportunity structures are constituted through interactions between algorithms, political actors, and online audiences. I argue that the algorithmic opportunity structures of major social media platforms can help to explain the recent growth of right-wing populism on social media. 
In particular, I focus on engagement-based algorithmic ranking and recommendation systems. These algorithms rank the content on users' Facebook News Feed or Twitter Timeline and select new items of content to recommend. One of the main signals used by these algorithms is engagement, the interactions between users and content, such as "likes," "shares," and "comments" on Facebook and "likes," "retweets," and "replies" on Twitter. Ranking and recommendation algorithms use these signals to identify content that resonated with a users' friends or other users with similar profiles (Bucher 2012). These algorithms often prioritize content with high engagement, which in turn increases the visibility of such content and hence the probability of further engagement. Sociological research on rankings shows that such systems can produce patterns of cumulative advantage and inequality (Salganik, Dodds, and Watts 2006), resulting in the cultivation of gaming strategies as actors attempt to improve their position vis-àvis their competitors (Espeland and Sauder 2007). In order to compete for social media users' attention, political actors are incentivized to produce content that attracts high levels of engagement.

The kinds of content produced by right-wing actors appears be particularly effective at generating high levels of engagement. For example, social media posts containing negative emotional language, populist rhetoric, and references to out-groups all tend to attract a disproportionate share of engagement (Brady et al. 2017; Blassnig et al. 2019; Rathje, Van Bavel, and van der Linden 2021). An experiment conducted by Twitter found that right-wing political parties and media outlets attracted more engagement from users with algorithmically ranked timelines compared to a control group with reverse-chronological timelines, suggesting that the right benefits from "algorithmic amplification" (Huszár et al. 2021). Leaked internal research from Facebook reveals how the platform's algorithms push users towards extremist groups and 
amplified misinformation, toxicity, and violent content, leading some employees to conclude that the platform's "algorithms exploit the human brain's attraction to divisiveness" (Horwitz and Seetharaman 2020; Hagey and Horwitz 2021). While the algorithms used by social media platforms are proprietary "black boxes," the inner workings of which are closely guarded by their corporate owners (Pasquale 2015), digital trace data provides insights into the relationship between online activism and audience engagement (Golder and Macy 2014).

To understand this issue, I conduct a case study of Britain First (BF), a far-right social movement that campaigned against the perceived threat of Islam to British people, culture, and Christian heritage (Allen 2014). ${ }^{1} \mathrm{BF}$ organized rallies to protest the construction of mosques, as well as more radical direct actions, and used social media, particularly Facebook, to publicize these activities and share anti-Muslim propaganda. The group shared a mixture of extreme anti-Muslim material and more benign nationalistic content designed to resonate with the sensibilities of the British public. BF attempted to game Facebook's ranking and recommendation algorithms by directly calling for users to "like," "share," and "comment" on this material in an effort to maximize engagement. This tactic appears to have been highly effective, as many of its posts attracted huge levels of engagement and it rapidly built a large online following. The group eventually attracted over two million followers on the platform, making it the most followed political organization in the country until it was banned for repeated policy violations and inciting hatred against minority groups (Facebook 2018).

To understand how BF used Facebook to build its online base, I analyze three related aspects of BF's online mobilization efforts: the volume of the group's activity, its recruitment of new social media users to "like" its page, and its ability to sustain the engagement of its existing supporters. I adopt a processual perspective (McAdam 2010), considering each outcome as an 
unfolding process, capturing the ebbs and flows of mobilization over a three-year period using data collected from Facebook. I consider the extent to which each of these processes is related to user engagement, as well as variation in the content of BF's posts, which I measure using structural topic modeling (Roberts et al. 2014). I situate BF's online activism within the context of offline political and discursive opportunity structures, considering the role of protests, events, and media coverage. The relationships between these factors are analyzed using time series regression. I use an error-correction model to account for the way each series develops over time (De Boef and Keele 2008) and to identify dynamic equilibria between time series, known as cointegration (Enns et al. 2017; Philips 2018). I also implement model-based simulations to provide more interpretable insights into the dynamic relationships between online activism and engagement (Jordan and Philips 2019).

I find that changes in BF's activity, support, and recruitment were generally endogenous to social media. The movement's online activity fluctuated in response to the engagement of online audiences; its supporters' engagement changed as a function of both BF's activity and audience engagement; and its ability to recruit new Facebook users was largely a function of prior engagement. The results show strong evidence of cointegration, which indicates the presence of feedback loops between these processes as activity begets engagement and engagement begets further engagement. A handful of topics were associated with substantial short-term spikes in recruitment and support, but there is little evidence that variation in the content of BF's posts had any long-term effects. The results also show that BF and its supporters responded in the short-term to exogenous factors including terrorist attacks and elections, whereas BF's protests and media coverage had no discernable impact on support or recruitment. 
This case study demonstrates how BF exploited Facebook's algorithms to its advantage by producing content optimized for engagement as a tactic to rapidly build its online audience. Supplementary analyses further highlight the feedback loops between online activism and engagement, illuminating the complex system of relationships between actors, audiences, and algorithms. I conclude by contextualizing these findings, considering how far-right groups can use social media to activate latent bases of support (John and Margetts 2009) and broaden their reach to new audiences, particularly when they are constrained by other institutions (Klein and Muis 2019). It is essential that social scientists interrogate the role of algorithms in contemporary politics, understand how these algorithms can help or hinder different kinds of activism, and critically assess the efforts of social media platforms to address these emerging issues.

\section{BACKGROUND}

\section{Far-right activism on social media}

Far-right activists have used the internet to organize and communicate since the early 1990 s, when neo-Nazis and Holocaust deniers had formed a network of interconnected websites, constituting a transnational "cyber-community” (Burris, Smith, and Strahm 2000). Far-right political parties used websites to bypass mainstream media, which often did not grant them the same amount of attention as mainstream parties, and to directly spread their message (Atton 2006). These websites developed into discussion forums, which enabled activists to actively discuss their views and develop collective identities. The most notable of these websites was Stormfront, an online community where white nationalists could discuss their views in relative privacy without the risk of stigmatization (Caren, Jowers, and Gaby 2012). By the mid-2000s, the online landscape had 
been transformed by the emergence of social media. Unlike discussion forums, which tend to attract those already embedded in far-right subcultures, social media sites could be used to reach a much broader audience. Platforms like Twitter and Facebook initially appeared to be the bedfellows of democratic and progressive movements including the Arab Spring uprisings, the Occupy movement, and the Indignados movement (Castells 2012; Gerbaudo 2012). More recently, it has become evident that these technologies have been used effectively by authoritarian regimes, far-right actors, and other anti-democratic groups (Tucker et al. 2017). While the political ascendancy of the right cannot be attributed to social media alone, there is a growing body of research indicating that far-right movements and parties have been particularly adept at using social media platforms to communicate and mobilize across a variety of settings.

In Germany, the anti-Islam PEGIDA movement and Alternative for Germany (AfD) party both have a large online presence and have received extensive scholarly attention (Stier et al. 2017; Klein and Muis 2019; Schwemmer 2021). Content produced by the AfD was shared more frequently on Facebook in the months before the 2017 federal election than that of all other parties combined. The Northern League party and neo-fascist Casa Pound movement in Italy both have a significant social media presence (Bobba 2019; Froio et al. 2020), with the leader of the former crediting Facebook for their electoral breakthrough in 2018: "Thank God we have the Internet, thank God we have Facebook" (Maza 2018). In India, the ruling Hindu nationalist party used social media to mobilize supporters (Sinha 2017) and instant-messaging application WhatsApp was used to spread rumors that incited communal violence (Arun 2019). The military and Buddhist nationalists in Myanmar also used Facebook to encourage violence against Muslim ethnic minorities (Fink 2019). Coordinated campaigns across Twitter, Facebook, and WhatsApp successfully promoted far-right outsider Jair Bolsonaro and spread misinformation about his rivals 
during the 2018 Brazilian presidential election (Evangelista and Bruno 2019). And in the United States, a top Facebook executive attributed Donald Trump's surprising victory in the 2016 Presidential election to the Trump campaign's use of digital advertising on the platform. ${ }^{2}$ Conservative politicians and activists continue to produce some of the most widely distributed content on Facebook (Roose 2020). A constellation of far-right and allied groups referred to as the "Alt-Right" has organized online and staged demonstrations across the country (Daniels 2018), culminating in the storming of the U.S. Capitol on January $6^{\text {th }}, 2021$.

Despite these trends, we know little about why these right-wing actors have been able to use social media so effectively. There is extensive research on the emergence of far-right political parties in the late twentieth century, mostly focusing on the European context (Ignazi 1992; Betz 1994; Kitschelt and McGann 1997). Most explanations tend to consider how macrostructural factors, particularly unemployment and immigration, and institutional factors like electoral systems affect the supply and demand of both far-right parties and movements (Jackman and Volpert 1996; Golder 2003; Muis and Immerzeel 2017; Vlandas and Halikiopoulou 2019). While these factors explain longer-term trends, they are typically slow changing and are inadequate for explaining the rapid, short-term growth of the far-right (Koopmans and Muis 2009), particularly on social media. More recent work suggests that right-wing activists have been more focused on using social media to share information and promote their ideologies, compared to left-wing groups that have been more focused on organizing (Schradie 2019; Freelon, Marwick, and Kreiss 2020). While this orientation may explain some of the recent growth of the right on social media, to understand these trends it is necessary to situate online activism within the algorithmicallymediated context of contemporary social media platforms. 


\section{Algorithmic opportunity structures}

The algorithms used by social media platforms have fundamentally altered the diffusion of information on the internet, creating new potential for online activism. Algorithms can be understood as computer code that take some form of input and through a sequence of operations, produce a specified output. They can vary in complexity from simple mathematical functions to complicated systems with almost innumerable inputs and outputs. Algorithms have become a ubiquitous part of our social lives (Burrell and Fourcade 2021), from the way their mediate our experiences on the internet (Bucher 2012; Gillespie 2014) to the transformation of organizational fields including law enforcement, journalism, and education (Brayne 2017; Caplan and boyd 2018; Christin 2018; Chu 2021). To theorize the implications of these developments for collective action, I bring together scholarship across the fields of social movements, communications, and technology.

Scholars of social movements emphasize how environmental factors such as political institutions, electoral rules, and divides within elite groups constitute political opportunity structures that impact the likelihood of protest and the probability protest will succeed, as well as the types of claims made by movements and their strategic and tactical decisions (McAdam 2010; Kitschelt 1986; Meyer and Minkoff 2004). In contrast to the structuralist tendencies in early formulations of the concept, subsequent work has emphasized how opportunities alone are insufficient; opportunities must be perceived by political actors and are often subject to contestation (Gamson and Meyer 1996). The concept of discursive opportunity structures was proposed to capture the cultural dimensions of mobilization, describing how the media, institutions, and more diffuse cultural understandings and worldviews render some ideas "visible" and "legitimate," while others are marginalized or delegitimated (Ferree 2003; Koopmans and 
Olzak 2004). I argue that the algorithms deployed to rank content on social media platforms operate in similar yet distinct ways to political and discursive opportunity structures. Like institutions, algorithms structure and regulate behavior, providing a framework for interaction (Napoli 2014). Like the media, algorithms moderate what becomes visible to online audiences, to a large extent determining "a message's chances of diffusion in the public sphere" (Koopmans and Olzak 2004, 202). Unlike political institutions and the media, however, algorithms are technological assemblages designed and controlled by handful of corporate actors. Companies like Facebook and Twitter effectively have monopolistic control over large swathes of the digital public sphere with little oversight or regulation.

The concept of affordances clarifies the sociotechnical dimension of algorithms. Affordances are opportunities for action provided by the environment. Psychologist James Gibson ([1979] 2014) coined the term to describe how different animals used the same objects in distinct ways as a function of their varying perceptions of the use value of objects. The concept has been widely used by communications scholars to understand interactions between humans and technologies. Like political opportunities, affordances must be perceived by actors, and they are not purely social constructions, as technologies are designed in ways that render them more or less conducive to different kinds of social action (Winner 1980). Critically, "affordances are not exclusively properties of people or of artifacts," but are relational, constituted through interaction (Treem and Leonardi 2013). A key affordance of social media platforms is the way they are used to share information and interact at scale (boyd 2010). For example, the "retweet" button on Twitter is an affordance that enables users to easily relay information and broadcast it to their personal network. Such affordances are key to the way social movements have used social media to form activist networks and organize protest (Earl 2010; Earl and Kimport 2011; Bennett and 
Segerberg 2012). The role of algorithms as an affordance is less well understood (Nagy and Neff 2015), partly because the algorithms are "black boxes" (Pasquale 2015), meaning that their innerworkings are often obscured, and their operation is "invisible" to most users (Eslami et al. 2015).

Bringing together these literatures, this study theorizes the impact of algorithms on contemporary social movements. I introduce the concept of algorithmic opportunity structures to capture how these technological assemblages enable and constrain collective action. In particular, I focus on engagement-based ranking and recommendation algorithms, software developed to filter and rank the content to displayed to social media users. Whereas earlier iterations of platforms like Facebook, Instagram, and Twitter showed users content in reverse-chronological order, prioritizing the most recent posts by their friends and other accounts they follow, over the past decade these platforms have built algorithms to rank and recommend content. These algorithms sift through vast quantities of data, identifying the content most relevant to users in order to sustain attention and maximize advertising revenue (DiResta 2018; Tufekci 2018). To explain the relationship between algorithms and activism on social media, I consider the interactions between algorithms, audiences, and activists.

Ranking and recommendation algorithms must be understood as inherently relational (Emirbayer 1997) because they adaptively adjust their outputs in response to peoples' behavior and interactions. For example, Facebook's News Feed ranks content using a complex array of indicators including users' past behavior, their friends' interests and activities, and the information about other users with similar behavioral patterns (Bucher 2012). In practice, these systems often prioritize the content most popular with other users. This reliance on these signals can produce feedback loops, as popular content gets recommended more, leading to further engagements and recommendations (Tufekci 2018). Sociological research demonstrates how such ranking systems 
can exacerbate inequality by producing Matthew Effects, where popularity begets further popularity (Salganik, Dodds, and Watts 2006). These popularity signals can have tangible influences on political behavior, as small cues indicating whether a user's Facebook friends voted in an election can increase election turnout (Bond et al. 2012). Even subtle changes to the emotional valence of the content in users' News Feed can influence their subsequent expressions (Kramer, Guillory, and Hancock 2014).

Ranking and recommendation algorithms can help or hinder collective action by moderating whether certain information becomes visible to online audiences. For example, Twitter was accused of censorship when the \#occupywallstreet hashtag did not appear in the platform's "Trending" topics section, despite widespread discussion of the protests, leading the company to explain that the usage of the hashtag had not met the algorithm's criteria (Gillespie 2012). Similarly, early posts about racism and police brutality in Ferguson, Missouri were overshadowed on Facebook because they did not receive much positive engagement, in contrast to the concurrent Ice Bucket Challenge, which was heavily promoted by the platform's algorithms due to high levels of positive engagement (Tufekci 2018). These examples show how algorithms can play a similar gatekeeping role to the mass media (Gamson and Wolfsfeld 1993), although editorial control is largely delegated to complex systems of computer code rather than direct human judgment and expertise (DiResta 2018). Platforms have the power to modify this code in ways that can render certain strategies defunct overnight, making algorithms a relatively volatile opportunity structure (Gamson and Meyer 1996). For example, changes to Facebook's algorithms have drastically changed the fates and fortunes of media organizations. Publishers like BuzzFeed and Upworthy experienced tremendous growth by creating easily digestible stories with compelling titles that 
generated high rates of engagement, but saw large drops in traffic when the company altered its algorithms to reduce "clickbait" (Caplan and boyd 2018).

While algorithms can impose constraints on activism, it is critical to consider how activists and other actors both interact with algorithms and attempt to use them to their advantage. The literature on affordances emphasizes how actors recognize the potential benefits from using specific features of technologies through an interactive process (Nagy and Neff 2015). Although the inner workings of algorithms used by social media platforms are opaque, activists attempt to "reverse-engineer" them to identify the most effective tactics (Tufekci 2018). Qualitative research demonstrates how activists use audience engagement and other signals provided by platforms as a way to monitor their audiences' reactions and adjust their activities accordingly (Busher 2017; Schradie 2019). These metrics can be leveraged to quantify the "resonance" of different messages to identify the most effective types of appeals (Ferree 2003). For example, PEGIDA strategically adapted its social media content to focus on the issue of immigration, recognizing that the issue was highly salient with its Facebook followers (Schwemmer 2021). Activists may "reactively" adjust their tactics in response to this feedback and develop gaming strategies to improve their position in the outputs of ranking algorithms (Espeland and Sauder 2007). The low cost of digital communication enables activists to easily test many different messages allowing them to identify what works through a trial-and-error process, although too much experimentation with messaging can be detrimental (Bail 2016b).

Far-right political parties and social movements may be particularly successful at exploiting these algorithmic opportunity structures due to the types of discourse they use online. Facebook posts by nationalist and populist parties tend to elicit more emotive responses, particularly "angry" reactions (Jost, Maurer, and Hassler 2020; Muraoka et al. 2021) and posts 
eliciting emotional reactions are associated with high rates of virality (Bail 2016a; Brady et al. 2017). Far-right parties also tend to make more populist appeals on social media than other parties (Ernst et al. 2017), and populist discourse - which evokes Manichean distinctions between the "pure" people and the "corrupt" elite and their purported allies (Mudde and Rovira Kaltwasser 2018) — is associated with high levels engagement (Blassnig et al. 2019). Additionally, mentions of out-groups are one of the biggest predictors of engagement on Facebook and Twitter (Rathje, Van Bavel, and van der Linden 2021). These findings suggest that far-right actors attract high

levels of engagement - the key input to ranking and recommendation algorithms — by using emotional rhetoric, evoking populist distinctions, and targeting out-groups. This engagement allows their messages to become algorithmically amplified and broadcast to larger audiences. By incentivizing actors to produce content that attracts engagements, ranking and recommendation algorithms may be encouraging right-wing actors to produce more and more extreme content.

\section{Events, protest, and media coverage}

Online activism does not occur in a vacuum but must be situated in the context of the wider political environment. Therefore, I also consider the degree to which protests, events, and media coverage may help to explain variation in online activism and the ascendancy of the far-right on social media. An important characteristic of any social movement is its capacity to mobilize people to engage in collective action. Existing work highlights the interconnections between protests and social media activity, showing how social media platforms have been used to develop collective identities and shared grievances, to organize collective action events, to spread awareness of protests, and to attract new recruits (González-Bailón et al. 2011; Earl et al. 2013; Budak and Watts 2015). Offline mobilization can increase engagement from online audiences, which can in turn 
stimulate more offline participation (Tufekci and Wilson 2012). Most work on online activism has studied left-wing movements, emphasizing the linkages between social media and street protests, but far-right activism tends to be more focused on advocacy than organizing, so the connection to protest may be weaker (Schradie 2019; Freelon, Marwick, and Kreiss 2020). Moreover, online movements are often decoupled from offline actions, with evidence that some movements with large virtual support bases were able to do little to mobilize people to act, even in relatively loweffort capacities such as donating to fundraisers (Lewis, Gray, and Meierhenrich 2014).

Events can modify opportunity structures, altering the potential for activism and the salience of different frames (Meyer and Minkoff 2004). Historical sociologists have studied how events affect public perceptions and emotions, enabling new possibilities for political transformations (Sewell 1996; Wagner-Pacifici 2010) and political scientists have demonstrated how public opinion fluctuates in response to events (Berinsky 2007). Terrorist attacks are an idealtypical example of "unanticipated event" (Ostrom and Simon 1985) and derive much of their potency from their unpredictability. There is evidence that terrorism can increase short-term antiimmigrant sentiment (Boomgaarden and de Vreese 2007; Legewie 2013) creating discursive opportunities for far-right mobilization. For example, the English Defence League (EDL) responded to the 2013 murder of a British soldier by Islamic extremists by organizing protests and writing hundreds of posts about the attack, attracting tens of thousands of new supporters in less than a week (Williams and Burnap 2016). Schwemmer (2021) argues that far-right actors adapt the content of their social media posts to such events, sharing more xenophobic content in less eventful periods as a way to try to sustain their audiences' attention. Elections, in contrast, are routine, anticipated events and constitute important opportunities to mobilize and influence institutionalized politics (McAdam and Tarrow 2010). Far-right social movements have mobilized 
online during elections in support of right-wing populist political parties (Stier et al. 2017; Davidson and Berezin 2018). While elections may be associated with heightened mobilization, this might be offset by the heightened attention paid to political parties.

The mass media has traditionally played an important gatekeeping role and many social movements have made media coverage a key part of their strategy and tactics (Gamson and Wolfsfeld 1993; Koopmans 2004). Media attention can produce positive feedback loops by creating heightened publicity and attention that helps to sustain mobilization (Seguin 2016). With respect to the far-right, the issue of media coverage has been hotly contested: activists argue that the media portrays them unfairly, while their opponents blame the media for providing free publicity (Muis and Immerzeel 2017; Ellinas 2018). The empirical evidence is mixed, showing that media attention can both help and hinder far-right parties and movements (Koopmans and Olzak 2004; Koopmans and Muis 2009; Skocpol and Williamson 2012). Social media have arguably reduced social movements' dependence on mass media, enabling them to reach people directly without any mediation (Caren, Andrews, and Lu 2020). Right-wing activists have developed an ecosystem of alternative media outlets that amplify their claims and bypass gatekeeping (Freelon, Marwick, and Kreiss 2020). Movements can easily produce their own textual and audiovisual content and disseminate it directly to their supporters, without the constraint of needing to appeal to the media. Online movements may therefore be able to spread awareness and recruit supporters without substantial media coverage.

\section{CASE STUDY: BRITAIN FIRST AND FACEBOOK}

This study considers the case of Britain First (BF), a far-right, anti-Muslim social movement. BF used social media to attract attention and rapidly build an audience of an unprecedent scale, making 
it an ideal candidate for exploring the dynamics of online activism. By mid-2017, BF had accumulated over two million likes on Facebook, making it the most widely followed political organization in the UK. The group was founded in 2011 by former members of the British National Party (BNP) to campaign against "anti-Christian discrimination," but quickly pivoted its focus to Islam, which has become a cause célèbre among far-right populist parties and movements in Europe (Brubaker 2017). BF framed itself as defending British people, culture, and values against the purported threats of Islamic extremism and sharia law (Allen 2014). The group organized dozens of marches across the UK, protesting against the construction of new mosques and alleged child sexual exploitation by "grooming gangs." Most controversially, the group engaged in "mosque invasions," where its activists entered mosques and harassed worshippers, and "Christian patrols," militaristic marches through neighborhoods in London with large Muslim populations. It also made some unsuccessful attempts to run candidates in local elections, including the London mayoral race. After failing in the electoral arena, BF used its platform to support the UK Independence Party (UKIP) and the Brexit referendum campaign (Davidson and Berezin 2018).

[FIGURES 1 AND 2 HERE]

BF relied upon a variety of online platforms including Twitter, YouTube, and its website to promote its views, attract supporters, and fundraise, but Facebook was its most potent organizing tool. Figure 1 shows BF's Facebook page in August 2017. In the center, there is a typical example of an anti-Muslim post, linking to a story on BF's leader Paul Golding's website. This page was used to share extreme anti-Muslim content, images and videos from BF's protests, and an eclectic assortment of more innocuous, nationalistic content. Figure 2 shows a sequence of images posted 
by $\mathrm{BF}$ in 2017. Note how more extreme material — two posts promoting protests against mosques and one supporting capital punishment-is interspersed with more benign, "banal" nationalist imagery evoking British identity and culture (Billig 1995). BF exploited the "resonance" of the more benign content as a way to attract attention of people who may not have identified with the far-right, later exposing them to its more "radical" claims about Islam and Muslims (Ferree 2003). Many of the images BF shared were overlaid with text directly asking social media users to engage via the "like", "share", and "comment" buttons. Such content has been characterized as "engagement bait" by Facebook, which considers these messages to be attempts to game the platform's News Feed algorithm to maximize "reach," or the number of unique users who view a particular item of content (Facebook 2017). There is evidence that this tactical innovation was successful, as millions of people engaged with BF and some of its posts went "viral," spreading widely through the social network (Hope Not Hate 2014). The group boasted about its reach, declaring on September 29 th 2014 , that its "Facebook page [was] seen by over 50 million people in the last 7 days - more than Labour, Conservative, and Lib-Dem combined!". This suggests that BF capitalized upon the algorithmic opportunity structure afforded by Facebook's News Feed algorithm to attract millions of online followers. The following analysis quantifies the group's activities on Facebook over a three-year period of sustained mobilization using a processual perspective (McAdam 2010), considering how key aspects of BF's online activism ebbed and flowed over time in response to both endogenous and exogenous factors.

\section{DATA}

Data from Britain First's Facebook page were collected using Facebook's Pages Application Programming Interface (API). I collected all posts published by the group, including the date and 
time, any associated text, and information on engagements. There were three types of engagements available to Facebook users: "likes," which people can use to express their agreement with a post; "comments" written directly in response to the post or other users' comments; and "shares," which allows users to relay the post to their personal networks. I collected user identification numbers (UID) associated with these engagements to trace the behavior of individual users over time. ${ }^{3} \mathrm{BF}$ was active on Facebook from October 2013 until March 2018, when it was banned from the platform. I restrict the analyses to the three-year period from April 1 ${ }^{\text {st }}, 2014$, until May $21^{\text {st }}, 2017$, because the group's activity was highly variable during the first several months and towards the end of its tenure on the platform (several periods had no activity due to enforcement actions by Facebook). This extreme temporal heteroskedasticity makes time series inference intractable. Moreover, changes to Facebook's API in May 2017 meant that UIDs were no longer included in the results, making it impossible to define key dependent variables. The goal of present analysis is therefore not to explain the entire trajectory of BF's career on Facebook, but rather to understand the dynamics of online activism during an extended period of sustained mobilization.

I collected additional data on protests, events, and media coverage from a variety of sources. Facebook posts, YouTube videos, and newspaper reports were used to compile a timeline of BF's protests. I restrict the focus to mass protest events, excluding direct actions involving a small cadre of activists, such as the aforementioned mosque invasions, which were not typically advertised in advance. In total, fifteen protests occurred during the period considered. Six Islamic extremist terrorist attacks that occurred in Europe or killed British citizens were identified using Wikipedia. ${ }^{4}$ There was approximately one major election each year in the period studied: the 2014 local and European parliament elections, the 2015 general election, and the 2016 Brexit referendum. To measure coverage of $\mathrm{BF}$ in the mainstream media, I used LexisNexis to collect 
newspaper articles mentioning the group from seven major national newspapers. ${ }^{5}$ In total, 471 articles including the term "Britain First" were identified. The coverage was almost universally negative and mostly in left-leaning papers.

\section{Dependent variables}

There are three dependent variables of interest: Britain First's online activity, its supporters' engagement, and the recruitment of new supporters. Each variable is represented as a time series and aggregated at the weekly-level. ${ }^{6}$ Figure 3 shows each dependent variable over time. The top panel represents BF's activity, defined as the number of posts published each week on the group's Facebook page. On average, $\mathrm{BF}$ posted $253(\mathrm{SD}=98.4)$ times each week, equating to around 36 posts per day. The series exhibits an upwards trend, showing that BF gradually increased the volume of content shared over time.

\section{[FIGURE 3 HERE]}

For the remaining two dependent variables, I use Facebook UIDs to count the unique users who liked BF's posts. I use likes rather than comments because likes are relatively unambiguous measure of agreement (Stier et al. 2017), whereas comments can also be written by people who oppose the group. ${ }^{7}$ Following prior work, I measure recruitment by counting the number of new users who engaged with the BF's content (González-Bailón et al. 2011; Bail 2016c), specifically the new users who liked BF's posts each week. The middle panel of Figure 3 shows the weekly levels of recruitment over the period. There are considerable fluctuations in this series, particularly in 2014, consistent with the existing evidence that BF attracted a large number of people around this time by posting engagement bait. On average, 48, $774(\mathrm{SD}=75,570)$ new Facebook users liked BF's posts each week. At the maximum, more half a million new Facebook users liked the group's 
posts in a single week - over a quarter of a million of them on a single day. This series exhibits a downward trend as the group gradually exhausted the pool of potential recruits.

Finally, an active user is defined as someone observed to like one or most posts by BF on a particular day and has liked at least one other posts in the past 30 days. ${ }^{8}$ This captures users who have repeatedly engaged with the group's content. BF's online support is measured by counting the number of active users each day and taking the weekly average. The bottom panel of Figure 3 shows support over the period considered. On average there were 23,303 ( $\mathrm{SD}=9,471)$ daily active users in a week. Although there are several large spikes in activity, unlike the recruitment series there is no clear trend. Each dependent variable and all independent variables related to social media engagement are log-transformed to account for skewed distributions. ${ }^{9}$

\section{Independent variables}

Variables measuring the weekly number of likes, comments, and shares are included to account for the effect of social media engagement. The recruitment and support models include as an independent variable but omit the weekly likes variable due to collinearity. Media mentions are included as a count variable denoting the number of newspaper articles mentioning BF each week. Dummy variables indicate whether elections, terrorist attacks, and protests occurred on a particular week. I add one-week leads and lags to capture the of anticipation and response to events, with the exception of terrorist attacks, where leads are omitted. For the Brexit referendum, I add an additional dummy for all weeks following the referendum to capture whether BF or its supporters changed their online behavior in response to the outcome, which has become a central feature of political contestation in the UK. The timing of all events is shown using vertical lines in Figure 3. 
Finally, it is important to account for the content of BF's posts because variation in topical content predicts engagement on social media (Bail 2016b; Bail, Brown, and Mann 2017; Schwemmer 2021). I use the text extracted from BF's Facebook posts to train a structural topic model (Roberts et al. 2014), an inductive approach that identifies latent topics based on the assumption that each text contains a mixture of different topics. These topics should correspond to the frames, narratives, and other discourse used in BF's communications (DiMaggio, Nag, and Blei 2013). After assessing several specifications, I use a model with 30 topics. The training and validation procedures discussed in Appendix B. As is typical in such analyses, not all topics are interpretable and some are excluded from the following analysis (Bail, Brown, and Mann 2017; Karell and Freedman 2019). I grouped the remaining topics into two categories. I identified six clusters of topics related to issues frequently emphasized in BF's posts, termed issue topics. Two of these - Crime and Military - are single topics, while the remaining four-Islam, Terrorism, Immigration, and Politics - are "metatopics," composites of two or more distinct but closely related topics (Wilkerson and Casas 2017). ${ }^{10}$ Second, I identified four topics pertaining to the movement and its mobilization efforts, which I refer to as instrumental topics because they related to particular aspects of BF's strategy. The Motivational topic captures discourse intended to motivate the group's supporters to act, consistent with Snow and Benford's (1988) concept of "motivational" framing. The Repression metatopic captures grievances against Facebook for taking enforcement actions against the group and the British government for prosecuting BF's leaders for religiously aggravated harassment. The Promotional metatopic includes topics related to the promotion of BF's website, merchandise, and the group's appeals to Facebook users to engage with its content. Finally, the Protests topic captures discussion related to the organization of BF's protests. Examples of posts containing each (meta)topic are shown in Table 1 (see Appendix B for an extended version, disaggregated by topic). I construct variables measuring the 
mean percentage of each (meta)topic in BF's posts in a given week and include these in the two models predicting recruitment and support.

\section{[TABLE 1 HERE]}

\section{METHODOLOGY}

\section{Nonstationarity, Cointegration, and the Error Correction Model}

Each outcome is measured repeatedly at regular intervals making these data suitable for time series analysis, an ideal method for studying social processes within a single case study (Abbott 1992). I begin by examining the temporal properties of each series. A time series is defined as stationary if it has a constant mean and variance over time and nonstationary if these assumptions are violated. Nonstationary data often indicate the presence of a "unit root," meaning that the series has a long (or even infinite) memory and shocks tend to persist for a relatively long time (Box-Steffensmeier et al. 2014). If this property is not taken into account, regression models will produce spurious results and inflated $R^{2}$ statistics (Engle and Granger 1987). Diagnostic tests indicate the presence of unit roots in all dependent variables and almost all independent variables (Appendix C). Nonstationary series can be transformed into stationary series by taking the first-difference, $\Delta x_{t}=$ $x_{t}-x_{t-1}$. I apply this transformation to each series and repeat the tests, finding that all firstdifferenced series are stationary. Figure 4 shows each of the three dependent variables after log transformation and first-differencing. Each series now fluctuates around a constant mean, and while there is variation, there are no longer any clear trends.

[FIGURE 4 HERE] 
To model the relationships between different time series, I use the error correction model (ECM), which captures both the short-run dynamics and the long-run relationships between nonstationary time series (De Boef and Keele 2008). The ECM can also be used to test for cointegration, the existence of dynamic equilibria between nonstationary series. Formally, two nonstationary series are cointegrated if there exists a stationary linear combination of the series (Box-Steffensmeier et al. 2014). Theoretically, cointegration signals the presence of feedback loops between time series as they adjust towards equilibrium in response to shocks to each other. The ECM takes the following basic form and is estimated using ordinary least squares regression:

$$
\Delta y_{t}=\alpha_{0}+\alpha_{1} y_{t-1}+\beta_{0} \Delta x_{t}+\beta_{1} x_{t-1}+\varepsilon_{t} .
$$

The nonstationary outcome $y_{t}$ is transformed into a stationary variable by taking the firstdifference, where $\Delta y_{t}=y_{t}-y_{t-1}$. The change in the dependent variable is a function of its previous value in levels, $y_{t-1}$, and an independent variable, $x$, entered in both contemporaneous firstdifferences, $\Delta x_{t}$, and lagged levels, $x_{t-1}$. The coefficient $\alpha_{1}$ is known as the error correction term, capturing the rate at which $y_{t}$ returns to the long-run equilibrium between it and $x_{t}$, following a shock to $x_{t}$ (assuming the series are cointegrated). The coefficient should range from $[-1,0]$, where higher values indicate a more gradual return to equilibrium. The coefficient is expected to be negative because any adjustment moves in the opposite direction to disequilibrium (Keele, Linn, and Webb 2016). Values outside of this range show that the model is incorrectly specified and that cointegration is unlikely to be present. The coefficient on the first-differenced independent variable, $\beta_{0}$, captures the short-term effect of a change in $x$ on change in $y$, and the $\beta_{1}$ coefficient captures the long-run effect of the level of $x$ on the change in $y$. The ECM can be modified to 
include multiple independent variables, represented by the vector $X$, and event dummy variables, $Z$. Dummy variables are stationary and are therefore exogenous to cointegrating relationships.

$$
\Delta y_{t}=\alpha_{0}+\alpha_{1} y_{t-1}+\beta_{0} \Delta X_{t}+\beta_{1} X_{t-1}+\gamma Z_{t}+\varepsilon_{t}
$$

Here the effect of the dummy variables on the change in the dependent variable is captured by the vector of coefficients $\gamma$.

I use two approaches to test for cointegration. First, I verify that the following three conditions for cointegration is satisfied: (1) $y$ and $x$ contain unit roots; (2) the error correction parameter $\alpha_{1}$ is statistically significant using MacKinnon critical values (Ericsson and MacKinnon 2002); ${ }^{11}$ and (3) the coefficient for the lag of $x$ is statistically significant (Enns et al. 2017). The first condition is satisfied by the unit root tests explained above (with the exception of media coverage, which is stationary and therefore cannot enter into cointegrating relationships). ${ }^{12}$ Second, I test for cointegration using the bounds procedure (Pesaran, Shin, and Smith 2001; Philips 2018). The procedure consists of two different cointegration tests, an F-test to determine if the coefficients on variables appearing in lags are jointly equal to zero (considered the more reliable test), and a one-sided t-test evaluates whether the coefficient on the lagged dependent variable is equal to zero. In order for the assumptions of these tests to hold, the residuals must be "white noise," meaning that they are purged of serial correlation and normally-distributed. The bounds consist of a pair of critical values for each test. Cointegration can be accepted or rejected if the test statistic falls outside the interval between the critical values, but statistics within the interval are indeterminate. In this case, any statistic to the right side of the bounds indicates cointegration. The results of these cointegration tests are reported below. 
I employ model-based simulations to visualize the relationships between variables over time and provide a more substantive interpretation of the otherwise complicated statistical models. Using an algorithm developed by Jordan and Philips (2019), I simulate the effect of a shocks to independent variables on each dependent variable. Each time, a specified independent variable is shocked by a standard deviation while other variables are held at their means and differenced variables are set to zero (no change). Simulated coefficients are drawn from a multivariate normal distribution with means and variance equal to the estimated parameters from the original model, along with a small amount of stochastic noise. The process is repeated 10,000 times to produce a range of plausible estimates. Rather than using first-differences, I plot the effect of a shock to the level of a given independent variable on the level of the dependent variable over time.

\section{RESULTS}

\section{Error Correction Parameters and Bounds Tests}

I begin by analyzing the error correction parameters and the results of the cointegration tests which are critical to understanding the temporal dynamics of each process. In all models, the error correction terms, $\alpha_{1}$, and the coefficients for the lagged-dependent variables (LDV) are within the expected range and are statistically-significant at the relevant MacKinnon critical values. This suggests that the models are correctly specified and that cointegration is likely present. Table 2 shows the output from the model predicting BF's activity, where the outcome is the change in the number of posts published on the group's Facebook page each week. Both PSS tests agree that cointegration is present, as the test statistics to the right of the bounds. The $\alpha_{1}$ coefficient of -.464 indicates a relatively slow return to equilibrium, meaning that only $46 \%$ of a shock dissipated in 
over a week, implying that shocks to any cointegrated variables result in long-term shifts in BF's posting behavior.

Table 3 shows the results of two ECMs estimating the weekly change in recruitment. The first model includes the same covariates as the previous model with two exceptions: likes are excluded due to collinearity with the dependent variable and the previous dependent variable is included in both first-difference and lagged levels to account for the effect of activity. The results show evidence of an error correction process with a relatively rapid return to equilibrium. However, the Shapiro-Wilk test shows that the residuals are heteroskedastic, making the bounds test unreliable. The second model includes the topic covariates, improving the model fit and producing white noise residuals. This demonstrates the importance of accounting for the content of BF's posts in addition to the volume of activity. Both PSS tests agree that cointegration is present. The coefficient on the LDV is close to -1 , implying that recruitment rates rapidly return to equilibrium following shocks to any cointegrating variables.

Finally, the models explaining changes in BF's support are shown in Table 4, each including the same covariates as the recruitment models. Like the last set of models, the residuals are only white noise once the topic covariates are included. The regression diagnostics and the ttest support cointegration but the F-statistic is within the bounds, so the evidence is weaker than the previous models. The coefficients on the LDV for support show a gradual rate of adjustment to equilibrium, suggesting that shocks to support take longer to dissipate. Taken together, these results suggest that each outcome is cointegrated with dynamics endogenous to social media. BF's activity and support appear to gradually adjust to shocks to cointegrating variables, whereas recruitment returns to its equilibrium more rapidly. I now turn to the relationships between each 
outcome and social media activity and engagement, considering both contemporaneous and lagged relationships.

\section{[TABLES 1-3 \& FIGURES 5-9 ABOUT HERE]}

\section{Social Media Activity and Engagement}

Beginning with the model predicting BF's activity, there is evidence of a contemporaneous relationship between activity and likes: a one-percent change in the number of likes is associated with a $0.16 \%$ change in posts that week. This implies that the group responds immediately to fluctuations in audience engagement by increasing its output. Turning to the lagged variableswhich can be part of cointegrating relationships - there are positive coefficients for likes and comments. This indicates that BF's activity rates shifted in response to the prior week's engagement levels. A one-percent increase in the lagged level of each type of engagement is associated with $0.12 \%$ and $0.08 \%$ changes to BF's activity, respectively. These relationships are visualized in Figure 5. Each panel shows the simulated effect of a standard-deviation shock to a type of engagement on BF's posting behavior. The simulations run over a hypothetical thirteen-

week period, with the shock occurring at week 5 , and the effects tracked for the next two months (weeks 6-13). Note that each series trends upwards over time, consistent with the descriptive finding that BF gradually increased its output on Facebook over the period considered. A standarddeviation shock to the number of likes (Mean $=413,961, \mathrm{SD}=461,165)$ results in a rapid increase in the activity rate that lasts for several weeks. This is precisely what we should expect to see when two series are cointegrated, as a shift in one series has a long-term effect on the levels of another series. There is a similar, albeit more gradual effect of a shock to comments (Mean $=36,612, \mathrm{SD}$ 
$=14,914)$, with the increase in the activity rate persisting for most of the following two months. It is useful to compare this to the effect of a shock to shares, which is not cointegrated with changes in BF's activity. Despite the huge magnitude of a shock (mean $=484,943, \mathrm{SD}=896,948$ ), there is no discernable change in the level of activity.

Turning to recruitment, Facebook users' comments and shares appear to have a substantial impact on BF's ability to attract the engagement of new Facebook users, both contemporaneously and in the long-term. A one-percent change in each form of engagement in a given week is associated with respective $0.7 \%$ and $0.67 \%$ changes to the number of new recruits. A one-percent increase in the level of each variable in the previous week is associated with respective $0.57 \%$ and $0.58 \%$ increases in the change in recruitment in the current week. Thus, the engagement of Facebook users with BF's posts rather than the volume of BF's activity appears to be driving both immediate and longer-term increases in recruitment. Figure 6 shows the simulated effects of shocks to posts, comments, and shares on recruitment, illustrating how a shock to shares is associated with a particularly large and sustained increase in recruitment.

The final set of models show that BF's supporters responded in the short-term to both the group's activity and the engagement of other users. A one-percent change in the weekly number of posts is associated with a $0.37 \%$ change in supporter engagement. An analogous change in comments has a similar effect. A one-percent change in shares is associated with a $0.15 \%$ change in the number of active users engaged. When considering the lagged independent variables, only the effect of previous shares persists after accounting for topic covariates. The simulation results in Figure 7 show the effect of shocks to these variables in levels. Shocks to posts and comments appear to produce rapid increases in supporter engagement that quickly level off, whereas shocks to shares not only result in short term increases, but also produce more persistent changes to the 
level of support. While the results of the cointegration tests were inconclusive, the form of the relationship between support and shares observed in the simulation results is consistent with cointegration.

\section{Topical Content}

To what extent does the content of BF's posts impact the dynamics of recruitment and support? Time series representing the prevalence of relevant topics and metatopics are included in both firstdifferences and levels. Beginning with the recruitment model, the results show little evidence of any association between most topics and recruitment with two exceptions. Changes in the proportion of the Promotional metatopic $($ Mean $=10.9 \%, \mathrm{SD}=6.63 \%)$ and the Military topic $($ Mean $=3.08 \%, \mathrm{SD}=0.38 \%)$ in BF's posts are associated with large contemporaneous changes in recruitment: a one-percent change in the proportion of each topic in a given week is associated with $6.93 \%$ and $45.6 \%$ changes in recruitment, respectively. There is also some evidence that recruitment is cointegrated with the content of BF's posts. A one-percent increase in the Repression metatopic $($ Mean $=5.33 \%, \mathrm{SD}=1.03 \%)$ is associated with a $16.6 \%$ change in recruitment the following week. I simulated effects of a shock to these topics on recruitment, the results of which are shown in Figure 8. Shifts in the use of the Promotional posts has the largest impact on recruitment, resulting in an immediate spike and a sustained change in the level, although the model results do not show evidence of cointegration. The Repression and Military topics have far more modest effects on the overall levels of recruitment, particularly when compared to the effects of engagement discussed above.

For the support model, the results show that changes in the proportion of the Terrorism metatopic $($ Mean $=10.3 \%, \mathrm{SD}=3.86 \%)$ dampen supporter engagement: a one-percent increase in 
the topic is associated with an instantaneous $4.3 \%$ decrease in the dependent variable. Figure 9 shows that a standard-deviation shock to the Terrorism metatopic is associated with a subsequent decline in activity over the following couple of weeks. In contrast, a shift in attention to the Military topic results in a spike in supporter's activity: a one-percent increase is associated with a $34 \%$ change in support. None of the coefficients in levels are statistically significant. In contrast to the various effects of engagement, variation in the content of BF's posts appears to have a relatively short-lived impact on the volume of supporter engagement. These results show that most topics are unrelated to the dynamics of BF's recruitment or support. A handful of topics are associated with relatively large shifts in these outcomes, but there is only evidence of cointegration in one out of the twenty coefficients evaluated across the two models, indicating that the impact any change in content is generally short-lived.

\section{Protests, Events, and Media Coverage}

Finally, I consider the relationship between protests, events, and media coverage and BF's online activism. BF's street protests are not associated with any of the outcomes, neither immediately nor when included as leads and lags. Turning to events, BF's activity changed in response to both national elections and the Brexit referendum. There is a decrease in the magnitude of change in the week's following elections and an increase in posting the week of the Brexit referendum, which happened to be the most active week observed, as the group posted extensively to celebrate the outcome. However, the group's activity appears to have been dampened in the post-Brexit period. There is no association between elections and recruitment (the coefficient for post-Brexit is not significant after accounting for topic covariates) and a negative relationship between elections and support. Despite BF's extensive focus on the topic, terrorist attacks are not associated with any 
changes in activity but do appear to result in increases in supporter engagement. Similarly, there is evidence of a weak negative relationship between changes in media coverage and BF's activity, but this coverage does not appear to impact support or recruitment.

\section{DISCUSSION}

Time series regression and cointegration tests reveal the presence of feedback loops as the social movement, its online audience, and its existing supporters dynamically adjusted their behavior in response to one another. $\mathrm{BF}$ increased the volume of its social media output when it received more likes and comments on its posts; new Facebook users engaged with BF's content for the first time when this content was commented on and shared by other Facebook users; and BF's existing supporters were more active in response to both the likes and comments of Facebook users, as well as increases in the group's activity. These results are consistent with the theory that BF's strategic use of engagement bait allowed it to use Facebook's algorithms to its advantage by generating huge amounts of engagement to game the platform's ranking and recommendation algorithms.

These results point towards a complex system of relationships between online mobilization and social media engagement. To understand these relationships more holistically, I estimated three supplementary error correction models, each predicting a different type of engagement with BF's posts - likes, comments, and shares - as a function of both engagement and the three outcome variables. While it is unconventional to switch the ordering of dependent and independent variables, in this case there are strong theoretical reasons to expect causality to flow in both directions. Figure 10 represents all cointegrating relationships identified in both the main and supplementary models (supplementary regression tables are reported in Appendix E). This 
representation better illustrates the feedback loops between different dimensions of online activism, showing both simple dyadic loops (e.g., between activity and likes) and more complex cycles (e.g., from activity to support to comments and back to activity). It also draws attention to heterogeneity across different forms of engagement, as likes, shares, and comments are associated with different aspects of the online mobilization process, and each process, in turn, inspires different forms of engagement. This highlights how affordances of social media platforms provide a variety of opportunities conducive to different aspects of online activism.

The content of BF's posts was associated with substantial yet short-lived fluctuations in support and recruitment. Most notably, there were increases in recruitment during weeks when the group used a higher proportion of the Promotional metatopic, which includes appeals for people to directly engage with BF's social media content and website, lending further support to the claim that engagement bait was an effective tactic for attracting Facebook users to become involved with the group. Hundreds of thousands of people_-out of the millions who may have seen the content in their News Feeds - decided to follow the instructions contained in these posts and like, share, and comment on BF's content. Posts about alleged sanctions from Facebook and repression by British government also attracted more new members, while posts revering the military resonated with existing supporters and new recruits alike. The only content observed to have a dampening effect was the Terrorism metatopic, likely because users may have been less apt to like posts about terrorism, as a like in such contexts could feel like an endorsement of terrorism.

\section{[FIGURE 10 HERE]}

The results also indicate that online activism responded to exogenous factors. None of the models show evidence of any association between online activism and BF's protests, consistent with other work that finds far-right activism on the internet is largely decoupled from street protests 
(Schradie 2019; Freelon et al. 2020). BF changed its social media activity in response to elections, tending to post less the week after elections and in the period following the Brexit referendum. This is consistent with Heaney and Rojas' (2011) demobilization theory, as the results of these elections swung in a conservative direction. BF was also more active the week of the referendum to leave the European Union-its most active week recorded - when it celebrated the outcome, viewing Brexit as a way to regain national sovereignty and reduce immigration (Davidson and Berezin 2018). The group also adapted the content of its posts to changing circumstances, emphasizing salient issues both in anticipation of and in response to relevant events (Appendix B, Table B). Events were not associated with any changes in recruitment, but supporter engagement did increase in the immediate aftermath of terrorist attacks. Media coverage had little impact on the processes under study—only a modest negative relationship between media coverage and BF's activity was observed — consistent with the observation that social media has reduced movements' dependence upon conventional media (Tufekci 2018; Caren, Andrews, and Lu 2020). Nonetheless, the present study only accounts for articles that specifically mentioned the movement. It is plausible that more subtle shifts in public discourse, such as increasing hostility towards immigrants, created discursive opportunities for the group to mobilize (Koopmans and Olzak 2004). These results underscore the importance of situating online activism in the context of offline political opportunity structures (Klein and Muis 2019).

\section{CONCLUSION}

Analyzing the case of Britain First, this study argues that the far-right has been so successful on social media due to the exploitation of favorable algorithmic opportunity structures. BF produced content designed to attract large number of engagements from Facebook's users, engagements 
which likely led to its content being ranked more highly and recommended to more users by Facebook's algorithms, resulting in further engagement. These engagements provided information to the movement, allowing it to hone its messaging by identifying salient content. This enabled BF to reach and sustain the attention of a large audience. BF used this platform to act as a superspreader for xenophobic, anti-Muslim propaganda. Contemporary activism on social media must be understood as a complex system of interactions between political actors, online audiences, and algorithms.

I cannot directly observe Facebook's algorithms since the company strictly limits the data made available to researchers, but existing theory and evidence suggests that these patterns are unlikely to be purely the result of traditional diffusion processes. While large-scale diffusion events can occur without algorithmic-mediation, it is still relatively rare for any individual social media post to "go viral" (Goel, Watts, and Goldstein 2012). The pace of BF's initial recruitment effort and the sheer volume of engagements many of its early posts received—with many posts attracting hundreds of thousands of likes and shares - point towards algorithmic amplification. Leaked internal filings to the U.S. Securities and Exchange Commission provide strong evidence that Facebook's algorithms have amplified online extremism. A report from 2016 noted that " $64 \%$ of all extremist group joins are due to our recommendation tools", meaning that most people did not discover these groups organically, but were recommended by Facebook's algorithms (Horwitz and Seetharaman 2020). Internal experiments found that new users who followed mainstream conservative pages like Fox News or Donald Trump were quickly recommended "polarizing content," including pages promoting conspiracy theories like QAnon (Zubrow, Gavrilovic, and Ortiz 2021). 
To understand why groups like BF have been so effective at exploiting these opportunities, we must consider the interaction between the algorithmic opportunity structures and broader political and discursive opportunities. British politics has shifted rightwards over the past two decades as immigration has become a key issue for many voters (Ford, Jennings, and Somerville 2015). Despite favorable discursive opportunities, the far-right has faced difficulty breaking into institutionalized politics. The BNP was marginalized in the electoral arena, losing votes to the mainstream Conservatives and the radical right UKIP (Art 2011; Ford and Goodwin 2014; Goodwin 2014). Many voters sympathized with the BNP on key policies, with survey evidence showing that "a large sub-section of the British electorate might consider voting for an extreme right party" (John and Margetts 2009, 497), but much of this potential enthusiasm remained dormant due to closed political opportunity structures. Social media has arguably unlocked this potential, equipping the far-right with a platform to reach and activate latent supporters, and to persuade others (Busher 2017). Similar to the way that broadcast media can amplify the messaging of fringe organizations (Bail 2012), social media algorithms can be used to attract the attention of millions of people whom they would otherwise be unlikely to reach. In this case, the ascendancy of mainstream conservatives blocked the far-right in the electoral arena, contributing to the explosive online growth of extra-parliamentary groups like the EDL and BF, consistent with the observation that extremist movements tend to thrive online when institutionalized political opportunities are closed (Klein and Muis 2019).

Facebook modified its algorithms in 2018 to increase "meaningful social interactions" by emphasizing content shared by individual users rather than pages controlled by publishers and other actors. However, these changes had the unintended consequence of further amplifying extreme material. Internal research subsequently found that "[m]isinformation, toxicity, and 
violent content are inordinately prevalent among reshares" (Hagey and Horwitz 2021). Political strategists complained to Facebook that the platform "systematically rewards provocative, lowquality content", forcing them to post more "divisive and sensationalistic" material to compete for attention, fostering the perception that they were "trapped in an inescapable cycle of negative campaigning by the incentive structures of the platform" (Zubrow, Gavrilovic, and Ortiz 2021). This illustrates how algorithms can generate field-level isomorphism, as actors adapt their behavior in response to common incentive structures and their competitors' behavior (Napoli 2014; Caplan and boyd 2018; Christin 2018). It also points to the "algorithmic trade-offs" political actors must make, as competition for online attention can require them to produce content that conflicts with their ideology and other principles (Chu 2021).

Britain First's dependence on social media proved to be its Achilles' heel. In late 2017, the President of the United States, Donald Trump, retweeted a series of anti-Muslim videos shared by BF's deputy leader Jayda Fransen. The media attention that followed led Twitter to ban the group and its leaders. Facebook followed suit a few months later, banning BF and several other far-right groups from its platform, citing how BF "repeatedly posted content designed to incite animosity and hatred against minority groups" (Facebook 2018). BF was also barred from YouTube and dropped by its website provider. Almost overnight, $\mathrm{BF}$ lost its ability to communicate with the vast majority of its supporters. Its leaders and more dedicated activists moved to even less regulated platforms like Gab, but these sites have much small user bases, limiting the group's ability to reach larger audiences (Zhou et al. 2019). ${ }^{13}$ As major social media platforms develop stronger policies against hate speech and other types of extreme content, such groups will either retreat to the fringes of the internet or be forced to change their tactics, much like the radical right in the electoral arena (Art 2011). Facebook subsequently changed its policies and the News Feed algorithm to reduce 
the power of engagement bait, potentially preventing others from emulating BF. These developments highlight the entanglement of contemporary politics with platform capitalism: the corporate architects and owners of these systems in Silicon Valley can unilaterally change the rules of the game in ways that can alter the flow of information in the public sphere and transform the potential for activism. It is therefore critical for scholars of political sociology to understand the interplay between the algorithms and policies of social media platforms and the behavior of political actors and audiences in response to these volatile opportunity structures.

\section{NOTES}

\footnotetext{
${ }^{1}$ I use the term "far-right" to refer to BF because the group's positions are at the fringe of right-wing politics in Britain and the group has been associated with violent activity. The term "extreme right" is sometimes used interchangeably. These terms can describe both political parties and social movements, e.g., the British National Party and the English Defence are both considered far- or extreme right. The term "radical right" refers to more mainstream right-wing parties like the UK Independence Party, which reject some aspects of liberal democracy but do not promote violence. I use the terms "right", "right-wing", and "conservative" in a more general sense to refer to actors to the right of the ideological spectrum. "Populism" refers to particular forms of political appeals often but not necessarily associated with the right and is defined in the main text. Many of the works cited use these terms interchangeably, contributing to conceptual confusion, see Rydgren (2007) and Muis and Immerzeel (2017) for further discussion.

${ }^{2}$ https://www.facebook.com/boz/posts/10111288357877121

${ }^{3}$ The API provided UIDs for likes and comments but not shares.

${ }^{4}$ The six terrorist attacks included are the shootings at Charlie Hebdo, Sousse, and Paris in 2015; the Brussels airport bombing and Nice truck attack in 2016; and the 2017 stabbing of a police officer at Westminster.

${ }^{5}$ The Guardian, The Independent, The Daily Mirror, The Times, The Telegraph, The Sun, and The Daily Mail.

${ }^{6}$ See Appendix A for discussion of temporal aggregation.

${ }^{7}$ I only consider standard likes and not the other kinds of reactions ("haha", "love", "wow", "sad", and "angry") Facebook introduced in spring 2016.

${ }^{8}$ These variables were defined using the untruncated data so active and new users are observed from day 1 of the present analysis.

${ }^{9}$ While the variables are counts, as I discuss below, they are modeled as first-differences and presence of negative values in the transformation makes count models unsuitable. In this case, it is preferable to use the natural logarithm to help account for temporal heteroskedasticity. This also makes the interpretation of the models more intuitive, as relationships between logged variables can be interpreted as elasticities.

${ }^{10}$ Each metatopic is a combination of multiple related subtopics. For example, the Terrorism metatopic consists of three topics: the Islamic State and conflict in the Middle East; terrorism in Europe; and a more general topic about Islamic extremism and jihad. See Appendix B for further details.

${ }^{11}$ The critical values are obtained from Table F of the Supplementary Manual of Enders (2015). The 1\% critical value is -4.831 and the $5 \%$ critical value is -4.182 .
} 
${ }^{12}$ Monte Carlo simulations using two regressors show that only one of the regressors need to cointegrate with the dependent variable to determine whether cointegration is present (Enns et al., 2017). The addition of the stationary media coverage variable should therefore not affect inferences regarding other variables.

${ }^{13}$ As of September $30^{\text {th }}$, 2021, BF has 13,622 followers on Gab (https://gab.com/BritainFirst). 


\section{REFERENCES}

Abbott, Andrew. 1992. "From Causes to Events: Notes on Narrative Positivism." Sociological Methods \& Research 20 (4): 428-55.

Allen, Chris. 2014. "Britain First: The 'Frontline Resistance' to the Islamification of Britain." The Political Quarterly 85 (3): 354-61.

Art, David. 2011. Inside the Radical Right: The Development of Anti-Immigrant Parties in Western Europe. Cambridge: Cambridge University Press.

Arun, Chinmayi. 2019. "On WhatsApp, Rumours, and Lynchings.” Economic \& Political Weekly 54 (6): 30-25.

Atton, Chris. 2006. "Far-Right Media on the Internet: Culture, Discourse and Power." New Media \& Society 8 (4): 573-87.

Bail, Christopher A. 2016a. "Emotional Feedback and the Viral Spread of Social Media Messages About Autism Spectrum Disorders." American Journal of Public Health 106 (7): 1173-80. . 2016b. "Cultural Carrying Capacity: Organ Donation Advocacy, Discursive Framing, and Social Media Engagement.” Social Science \& Medicine 165 (September): 280-88.

.2016c. "Combining Natural Language Processing and Network Analysis to Examine How Advocacy Organizations Stimulate Conversation on Social Media." Proceedings of the National Academy of Sciences 113 (42): 11823-28.

Bail, Christopher A., Taylor W. Brown, and Marcus Mann. 2017. "Channeling Hearts and Minds: Advocacy Organizations, Cognitive-Emotional Currents, and Public Conversation." American Sociological Review 82 (6): 1188-1213.

Bennett, W. Lance, and Alexandra Segerberg. 2012. "The Logic of Connective Action: Digital Media and the Personalization of Contentious Politics." Information, Communication \& Society 15 (5): 739-68.

Berinsky, Adam J. 2007. "Assuming the Costs of War: Events, Elites, and American Public Support for Military Conflict.” Journal of Politics 69 (4): 975-97.

Betz, Hans-George. 1994. Radical Right-Wing Populism in Western Europe. New York, NY: St. Martin's Press.

Billig, Michael. 1995. Banal Nationalism. Thousand Oaks, CA: SAGE Publications.

Blassnig, Sina, Nicole Ernst, Sven Engesser, and Frank Esser. 2019. "Populism and Social Media Popularity." In Power Shift? Political Leadership and Social Media, edited by Richard Davis and David Taras, 97-111. Routledge.

Bobba, Giuliano. 2019. "Social Media Populism: Features and 'Likeability' of Lega Nord Communication on Facebook." European Political Science 18 (1): 11-23.

Bond, Robert M., Christopher J. Fariss, Jason J. Jones, Adam D. I. Kramer, Cameron Marlow, Jaime E. Settle, and James H. Fowler. 2012. "A 61-Million-Person Experiment in Social Influence and Political Mobilization." Nature 489 (7415): 295-98.

Boomgaarden, H. G., and C. H. de Vreese. 2007. "Dramatic Real-World Events and Public Opinion Dynamics: Media Coverage and Its Impact on Public Reactions to an Assassination.” International Journal of Public Opinion Research 19 (3): 354-66.

Box-Steffensmeier, Janet, John R. Freeman, Matthew P. Hitt, and Jon C. W. Pevehouse. 2014. Time Series Analysis for the Social Sciences. New York, NY: Cambridge University Press.

boyd, danah. 2010. "Social Network Sites as Networked Publics: Affordances, Dynamics, and Implications." In A Networked Self, edited by Zizi Papacharissi, 47-66. Routledge. 
Brady, William J., Julian A. Wills, John T. Jost, Joshua A. Tucker, and Jay J. Van Bavel. 2017. "Emotion Shapes the Diffusion of Moralized Content in Social Networks." Proceedings of the National Academy of Sciences 114 (28): 7313-18.

Brayne, Sarah. 2017. "Big Data Surveillance: The Case of Policing." American Sociological Review, 1-32.

Brubaker, Rogers. 2017. "Between Nationalism and Civilizationism: The European Populist Moment in Comparative Perspective." Ethnic and Racial Studies 40 (8): 1191-1226.

Bucher, Taina. 2012. "Want to Be on the Top? Algorithmic Power and the Threat of Invisibility on Facebook." New Media \& Society 14 (7): 1164-80.

Budak, Ceren, and Duncan Watts. 2015. "Dissecting the Spirit of Gezi: Influence vs. Selection in the Occupy Gezi Movement.” Sociological Science 2: 370-97.

Burrell, Jenna, and Marion Fourcade. 2021. "The Society of Algorithms." Annual Review of Sociology 47 (1): annurev-soc-090820-020800.

Burris, Val, Emery Smith, and Ann Strahm. 2000. "White Supremacist Networks on the Internet." Sociological Focus 33 (2): 215-35.

Busher, Joel. 2017. "Why Even Misleading Identity Claims Matter: The Evolution of the English Defence League." Political Studies, 0032321717720378.

Caplan, Robyn, and danah boyd. 2018. "Isomorphism through Algorithms: Institutional Dependencies in the Case of Facebook." Big Data \& Society 5 (1): 205395171875725.

Caren, Neal, Kenneth T. Andrews, and Todd Lu. 2020. "Contemporary Social Movements in a Hybrid Media Environment." Annual Review of Sociology 46 (1): 443-65.

Caren, Neal, Kay Jowers, and Sarah Gaby. 2012. "A Social Movement Online Community: Stormfront and the White Nationalist Movement." In Research in Social Movements, Conflicts and Change, edited by Jennifer Earl and Deana A. Rohlinger, 33:163-93. Bingley: Emerald Group.

Castells, Manuel. 2012. Networks of Outrage and Hope: Social Movements in the Internet Age. Cambridge: Polity Press.

Christin, Angèle. 2018. "Counting Clicks: Quantification and Variation in Web Journalism in the United States and France." American Journal of Sociology 123 (5): 1382-1415.

Chu, James. 2021. "Cameras of Merit or Engines of Inequality? College Ranking Systems and the Enrollment of Disadvantaged Students." American Journal of Sociology 126 (6): 1307-46.

Cinelli, Matteo, Gianmarco De Francisci Morales, Alessandro Galeazzi, Walter Quattrociocchi, and Michele Starnini. 2021. "The Echo Chamber Effect on Social Media." Proceedings of the National Academy of Sciences 118 (9): e2023301118.

Daniels, Jessie. 2018. "The Algorithmic Rise of the 'Alt-Right." Contexts 17 (1): 60-65.

Davidson, Thomas, and Mabel Berezin. 2018. "Britain First and the UK Independence Party: Social Media and Movement-Party Dynamics." Mobilization: An International Quarterly 23 (4): 485-510.

De Boef, Suzanna, and Luke Keele. 2008. "Taking Time Seriously.” American Journal of Political Science 52 (1): 184-200.

DiMaggio, Paul, Manish Nag, and David Blei. 2013. "Exploiting Affinities between Topic Modeling and the Sociological Perspective on Culture: Application to Newspaper Coverage of U.S. Government Arts Funding." Poetics 41 (6): 570-606.

DiResta, Renee. 2018. "Computational Propaganda: If You Make It A Trend, You Make It True." The Yale Review 106 (4): 12-29.

Earl, Jennifer. 2010. "The Dynamics of Protest-Related Diffusion on the Web." Information, Communication \& Society 13 (2): 209-25. 
Earl, Jennifer, and Katrina Kimport. 2011. Digitally Enabled Social Change: Activism in the Internet Age. Cambridge, MA: MIT Press.

Earl, Jennifer, Heather McKee Hurwitz, Analicia Mejia Mesinas, Margaret Tolan, and Ashley Arlotti. 2013. "This Protest Will Be Tweeted: Twitter and Protest Policing during the Pittsburgh G20.” Information, Communication \& Society 16 (4): 459-78.

Ellinas, Antonis A. 2018. "Media and the Radical Right." In The Oxford Handbook of the Radical Right, edited by Jens Rydgren, 269-84. New York, NY: Oxford University Press.

Emirbayer, Mustafa. 1997. "Manifesto for a Relational Sociology." American Journal of Sociology 103 (2): 281-317.

Engle, Robert F., and C. W. J. Granger. 1987. "Co-Integration and Error Correction: Representation, Estimation, and Testing.” Econometrica 55 (2): 251-176.

Enns, Peter K., Nathan J. Kelly, Takaaki Masaki, and Patrick C. Wohlfarth. 2017. "Moving Forward with Time Series Analysis." Research \& Politics 4 (4): 1-7.

Ericsson, Neil R., and James G. MacKinnon. 2002. "Distributions of Error Correction Tests for Cointegration." The Econometrics Journal 5 (2): 285-318.

Ernst, Nicole, Sven Engesser, Florin Büchel, Sina Blassnig, and Frank Esser. 2017. "Extreme Parties and Populism: An Analysis of Facebook and Twitter across Six Countries." Information, Communication \& Society 20 (9): 1347-64.

Eslami, Motahhare, Aimee Rickman, Kristen Vaccaro, Amirhossein Aleyasen, Andy Vuong, Karrie Karahalios, Kevin Hamilton, and Christian Sandvig. 2015. "I Always Assumed That I Wasn't Really That Close to [Her]': Reasoning about Invisible Algorithms in News Feeds." In Proceedings of the 33rd Annual ACM Conference on Human Factors in Computing Systems, 153-62.

Espeland, Wendy Nelson, and Michael Sauder. 2007. "Rankings and Reactivity: How Public Measures Recreate Social Worlds." American Journal of Sociology 113 (1): 1-40.

Evangelista, Rafael, and Fernanda Bruno. 2019. "WhatsApp and Political Instability in Brazil: Targeted Messages and Political Radicalisation." Internet Policy Review 8 (4).

Facebook. 2017. "Fighting Engagement Bait on Facebook." Facebook. December 18, 2017.

—. 2018. "Taking Action Against Britain First." Facebook. March 14, 2018.

Ferree, Myra Marx. 2003. "Resonance and Radicalism: Feminist Framing in the Abortion Debates of the United States and Germany." American Journal of Sociology 109 (2): 304-44.

Fink, Christina. 2019. "Dangerous Speech, Anti-Muslim Violence, and Facebook in Myanmar." Journal of International Affairs 71 (1.5): 43-52.

Ford, Robert, and Matthew J. Goodwin. 2014. Revolt on the Right: Explaining Support for the Radical Right in Britain. London: Routledge.

Ford, Robert, Will Jennings, and Will Somerville. 2015. "Public Opinion, Responsiveness and Constraint: Britain's Three Immigration Policy Regimes.” Journal of Ethnic and Migration Studies 41 (9): 1391-1411.

Freelon, Deen, Michael Bossetta, Chris Wells, Josephine Lukito, Yiping Xia, and Kirsten Adams. 2020. "Black Trolls Matter: Racial and Ideological Asymmetries in Social Media Disinformation." Social Science Computer Review, April, 089443932091485.

Freelon, Deen, Alice Marwick, and Daniel Kreiss. 2020. "False Equivalencies: Online Activism from Left to Right." Science 369 (6508): 1197-1201.

Froio, Caterina, Pietro Castelli Gattinara, Giorgia Bulli, and Matteo Albanese. 2020. "CasaPound Italia: Hybridization in the Contemporary Extreme Right.” In CasaPound Italia, 1st ed., 1-21. Routledge. 
Gamson, William A., and David S. Meyer. 1996. "Framing Political Opportunity." In Comparative Perspectives on Social Movements: Political Opportunities, Mobilizing Structures, and Cultural Framings, 275-90. Cambridge University Press.

Gamson, William A., and Gadi Wolfsfeld. 1993. "Movements and Media as Interacting Systems." The Annals of the American Academy of Political and Social Science 528 (1): 114-25.

Gerbaudo, Paolo. 2012. Tweets and the Streets: Social Media and Contemporary Activism. London: Pluto Press.

. 2018. "Social Media and Populism: An Elective Affinity?" Media, Culture \& Society 40 (5): 745-53.

Gibson, James J. 2014. The Ecological Approach to Visual Perception: Classic Edition. Psychology Press.

Gillespie, Tarleton. 2012. "Can an Algorithm Be Wrong?" Limn 1 (2).

- 2014. "The Relevance of Algorithms." In Media Technologies, edited by Tarleton Gillespie, Pablo J. Boczkowski, and Kirsten A. Foot, 167-94. The MIT Press.

Goel, Sharad, Duncan J. Watts, and Daniel G. Goldstein. 2012. "The Structure of Online Diffusion Networks." In Proceedings of the 13th ACM Conference on Electronic Commerce, 62338. ACM.

Golder, Matt. 2003. “Explaining Variation In The Success Of Extreme Right Parties In Western Europe:" Comparative Political Studies 36 (4): 432-66.

Golder, Scott A., and Michael W. Macy. 2014. "Digital Footprints: Opportunities and Challenges for Online Social Research.” Annual Review of Sociology 40 (1): 129-52.

González-Bailón, Sandra, Javier Borge-Holthoefer, Alejandro Rivero, and Yamir Moreno. 2011. "The Dynamics of Protest Recruitment through an Online Network." Scientific Reports 1 (1): 197.

Goodwin, Matthew J. 2014. "Forever a False Dawn? Explaining the Electoral Collapse of the British National Party (BNP).” Parliamentary Affairs 67 (4): 887-906.

Hagey, Keach, and Jeff Horwitz. 2021. "Facebook Tried to Make Its Platform a Healthier Place. It Got Angrier Instead.” Wall Street Journal, September 15, 2021, sec. Tech.

Heaney, Michael T., and Fabio Rojas. 2011. "The Partisan Dynamics of Contention: Demobilization of the Antiwar Movement in the United States, 2007-2009." Mobilization: An International Quarterly 16 (1): 45-64.

Hope Not Hate. 2014. "Britain First: Army of the Right." London: Hope Not Hate.

Horwitz, Jeff, and Deepa Seetharaman. 2020. "Facebook Executives Shut Down Efforts to Make the Site Less Divisive." Wall Street Journal, May 26, 2020, sec. Tech.

Horwitz, Keach Hagey and Jeff. 2021. "Facebook Tried to Make Its Platform a Healthier Place. It Got Angrier Instead.” Wall Street Journal, September 15, 2021, sec. Tech.

Huszár, Ferenc, Sofia Ira Ktena, Conor O’Brien, Luca Belli, Andrew Schlaikjer, and Moritz Hardt. 2021. "Algorithmic Amplification of Politics on Twitter."

Ignazi, Piero. 1992. "The Silent Counter-Revolution: Hypotheses on the Emergence of Extreme Right-Wing Parties in Europe.” European Journal of Political Research 22 (1): 3-34.

Jackman, Robert W., and Karin Volpert. 1996. "Conditions Favouring Parties of the Extreme Right in Western Europe.” British Journal of Political Science 26 (04): 501-21.

John, Peter, and Helen Margetts. 2009. "The Latent Support for the Extreme Right in British Politics." West European Politics 32 (3): 496-513.

Jordan, Soren, and Andrew Philips Q. 2019. "Dynamic Simulation and Testing for SingleEquation Cointegrating and Stationary Autoregressive Distributed Lag Models." The $R$ Journal 10 (2): 469. 
Jost, Pablo, Marcus Maurer, and Joerg Hassler. 2020. "Populism Fuels Love and Anger: The Impact of Message Features on Users' Reactions on Facebook." International Journal of Communication 14: 2081-2102.

Karell, Daniel, and Michael Freedman. 2019. "Rhetorics of Radicalism." American Sociological Review 84 (4): 726-53.

Keele, Luke, Suzanna Linn, and Clayton McLaughlin Webb. 2016. "Treating Time with All Due Seriousness." Political Analysis 24 (1): 31-41.

Kitschelt, Herbert P. 1986. "Political Opportunity Structures and Political Protest: Anti-Nuclear Movements in Four Democracies." British Journal of Political Science 16 (1): 57-85.

Kitschelt, Herbert P., and Anthony J. McGann. 1997. The Radical Right in Western Europe: A Comparative Analysis. Ann Arbor, MI: The University of Michigan Press.

Klein, Ofra, and Jasper Muis. 2019. "Online Discontent: Comparing Western European Far-Right Groups on Facebook.” European Societies 21 (4): 540-62.

Koopmans, Ruud. 2004. "Movements and Media: Selection Processes and Evolutionary Dynamics in the Public Sphere." Theory and Society 33 (3-4): 367-91.

Koopmans, Ruud, and Jasper Muis. 2009. "The Rise of Right-Wing Populist Pim Fortuyn in the Netherlands: A Discursive Opportunity Approach." European Journal of Political Research 48 (5): 642-64.

Koopmans, Ruud, and Susan Olzak. 2004. "Discursive Opportunities and the Evolution of RightWing Violence in Germany." American Journal of Sociology 110 (1): 198-230.

Kramer, Adam D. I., Jamie E. Guillory, and Jeffrey T. Hancock. 2014. "Experimental Evidence of Massive-Scale Emotional Contagion through Social Networks." Proceedings of the National Academy of Sciences 111 (24): 8788-90.

Legewie, Joscha. 2013. "Terrorist Events and Attitudes toward Immigrants: A Natural Experiment." American Journal of Sociology 118 (5): 1199-1245.

Lewis, Kevin, Kurt Gray, and Jens Meierhenrich. 2014. "The Structure of Online Activism." Sociological Science 1: 1-9.

Maza, Cristina. 2018. "Far-Right Leader Thanks Facebook for Strong Election Results in Italy." Yahoo News, March 5, 2018.

McAdam, Doug. 2010. Political Process and the Development of Black Insurgency, 1930-1970. Chicago, IL: University of Chicago Press.

McAdam, Doug, and Sidney Tarrow. 2010. "Ballots and Barricades: On the Reciprocal Relationship between Elections and Social Movements." Perspectives on Politics 8 (2): 529-42.

Meyer, David S., and Debra C. Minkoff. 2004. "Conceptualizing Political Opportunity." Social Forces 82 (4): 1457-92.

Mudde, Cas, and Cristóbal Rovira Kaltwasser. 2018. "Studying Populism in Comparative Perspective: Reflections on the Contemporary and Future Research Agenda." Comparative Political Studies 51 (13): 1667-93.

Muis, Jasper, and Tim Immerzeel. 2017. "Causes and Consequences of the Rise of Populist Radical Right Parties and Movements in Europe." Current Sociology 65 (6): 909-30.

Muraoka, Taishi, Jacob Montgomery, Christopher Lucas, and Margit Tavits. 2021. "Love and Anger in Global Party Politics: Facebook Reactions to Political Party Posts in 79 Democracies.” Journal of Quantitative Description: Digital Media, 38.

Nagy, Peter, and Gina Neff. 2015. "Imagined Affordance: Reconstructing a Keyword for Communication Theory." Social Media + Society 1 (2): 205630511560338. 
Napoli, Philip M. 2014. "Automated Media: An Institutional Theory Perspective on Algorithmic Media Production and Consumption: Automated Media." Communication Theory 24 (3): 340-60.

Ostrom, Charles W., and Dennis M. Simon. 1985. "Promise and Performance: A Dynamic Model of Presidential Popularity." American Political Science Review 79 (2): 334-58.

Pariser, Eli. 2011. The Filter Bubble: What the Internet Is Hiding from You. London: Penguin UK. Pasquale, Frank. 2015. The Black Box Society. Harvard University Press.

Pesaran, M. Hashem, Yongcheol Shin, and Richard J. Smith. 2001. "Bounds Testing Approaches to the Analysis of Level Relationships." Journal of Applied Econometrics 16 (3): 289-326.

Philips, Andrew Q. 2018. "Have Your Cake and Eat It Too? Cointegration and Dynamic Inference from Autoregressive Distributed Lag Models.” American Journal of Political Science 62 (1): 230-44.

Rathje, Steve, Jay J. Van Bavel, and Sander van der Linden. 2021. “Out-Group Animosity Drives Engagement on Social Media." Proceedings of the National Academy of Sciences 118 (26): e2024292118.

Roberts, Margaret E., Brandon M. Stewart, Dustin Tingley, Christopher Lucas, Jetson Leder-Luis, Shana Kushner Gadarian, Bethany Albertson, and David G. Rand. 2014. "Structural Topic Models for Open-Ended Survey Responses." American Journal of Political Science 58 (4): 1064-82.

Roose, Kevin. 2020. "What If Facebook Is the Real 'Silent Majority'? - The New York Times." The New York Times, August 27, 2020.

Rydgren, Jens. 2007. "The Sociology of the Radical Right." Annual Review of Sociology 33 (1): 241-62.

Salganik, Matthew J., Peter Sheridan Dodds, and Duncan J. Watts. 2006. "Experimental Study of Inequality and Unpredictability in an Artificial Cultural Market." Science Reports 311: 854-56.

Schradie, Jen. 2019. The Revolution That Wasn't: How Digital Activism Favors Conservatives. Cambridge, MA: Harvard University Press.

Schwemmer, Carsten. 2021. "The Limited Influence of Right-Wing Movements on Social Media User Engagement." Social Media + Society, September, 1-13.

Seguin, Charles. 2016. "Cascades of Coverage: Dynamics of Media Attention to Social Movement Organizations.” Social Forces 94 (3): 997-1020.

Sewell, William H. 1996. "Historical Events as Transformations of Structures: Inventing Revolution at the Bastille." Theory and Society 25 (6): 841-81.

Sinha, Subir. 2017. "Fragile Hegemony: Modi, Social Media, and Competitive Electoral Populism in India." International Journal of Communication 11: 4158-80.

Skocpol, Theda, and Vanessa Williamson. 2012. The Tea Party and the Remaking of Republican Conservatism. New York, NY: Oxford University Press.

Snow, David A., and Robert D. Benford. 1988. "Ideology, Frame Resonance, and Participant Mobilization.” International Social Movement Research 1 (1): 197-217.

Stier, Sebastian, Lisa Posch, Arnim Bleier, and Markus Strohmaier. 2017. "When Populists Become Popular: Comparing Facebook Use by the Right-Wing Movement Pegida and German Political Parties." Information, Communication \& Society 20 (9): 1365-88.

Treem, Jeffrey W., and Paul M. Leonardi. 2013. "Social Media Use in Organizations: Exploring the Affordances of Visibility, Editability, Persistence, and Association." Annals of the International Communication Association 36 (1): 143-89. 
Tucker, Joshua A., Yannis Theocharis, Margaret E. Roberts, and Pablo Barberá. 2017. "From Liberation to Turmoil: Social Media And Democracy." Journal of Democracy 28 (4): 4659.

Tufekci, Zeynep. 2018. Twitter and Tear Gas: The Power and the Fragility of Networked Protest. New York, NY: Oxford University Press.

Tufekci, Zeynep, and Christopher Wilson. 2012. "Social Media and the Decision to Participate in Political Protest: Observations From Tahrir Square." Journal of Communication 62 (2): 363-79.

Vlandas, Tim, and Daphne Halikiopoulou. 2019. "Does Unemployment Matter? Economic Insecurity, Labour Market Policies and the Far-Right Vote in Europe." European Political Science 18 (3): 421-38.

Wagner-Pacifici, Robin. 2010. "Theorizing the Restlessness of Events." American Journal of Sociology 115 (5): 1351-86.

Wilkerson, John, and Andreu Casas. 2017. "Large-Scale Computerized Text Analysis in Political Science: Opportunities and Challenges.” Annual Review of Political Science 20: 529-44.

Williams, Matthew L., and Pete Burnap. 2016. "Cyberhate on Social Media in the Aftermath of Woolwich: A Case Study in Computational Criminology and Big Data.” British Journal of Criminology 56 (2): 211-38.

Winner, Langdon. 1980. "Do Artifacts Have Politics?” Daedalus 109 (1): 121-36.

Zhou, Yuchen, Mark Dredze, David A. Broniatowski, and William D. Adler. 2019. "Elites and Foreign Actors among the Alt-Right: The Gab Social Media Platform.” First Monday 24 (9).

Zubrow, Keith, Maria Gavrilovic, and Alex Ortiz. 2021. "Whistleblower's SEC Complaint: Facebook Knew Platform Was Used to 'Promote Human Trafficking and Domestic Servitude." CBS News, October 4, 2021. 


\section{FIGURES}

\section{Figure 1: Britain First's Facebook Page}

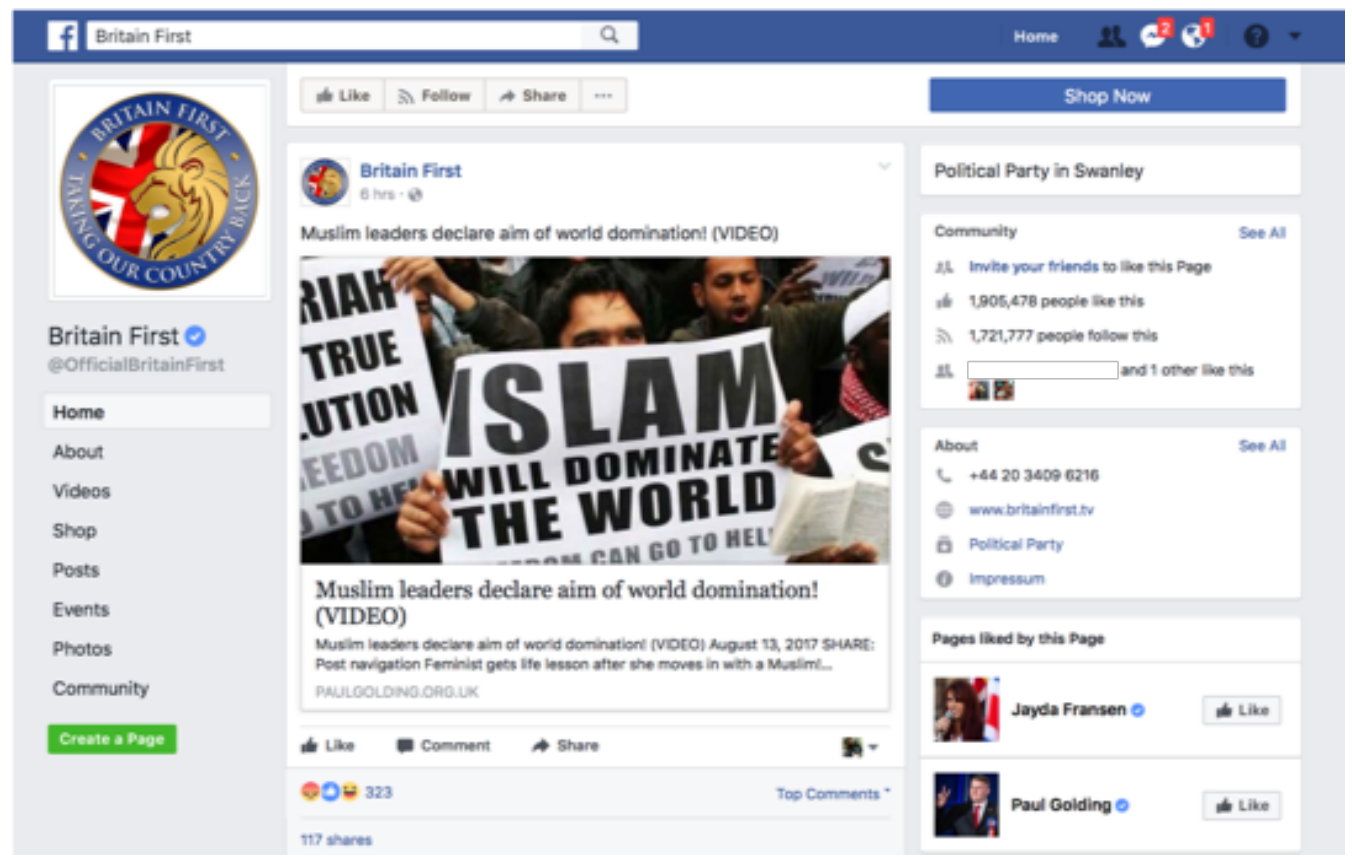

Note: Britain First's Facebook page shows a post linking to a video on the website of its leader, Paul Golding. Screenshot by the author, 2017. 
Figure 2: Images posted on Facebook by Britain First
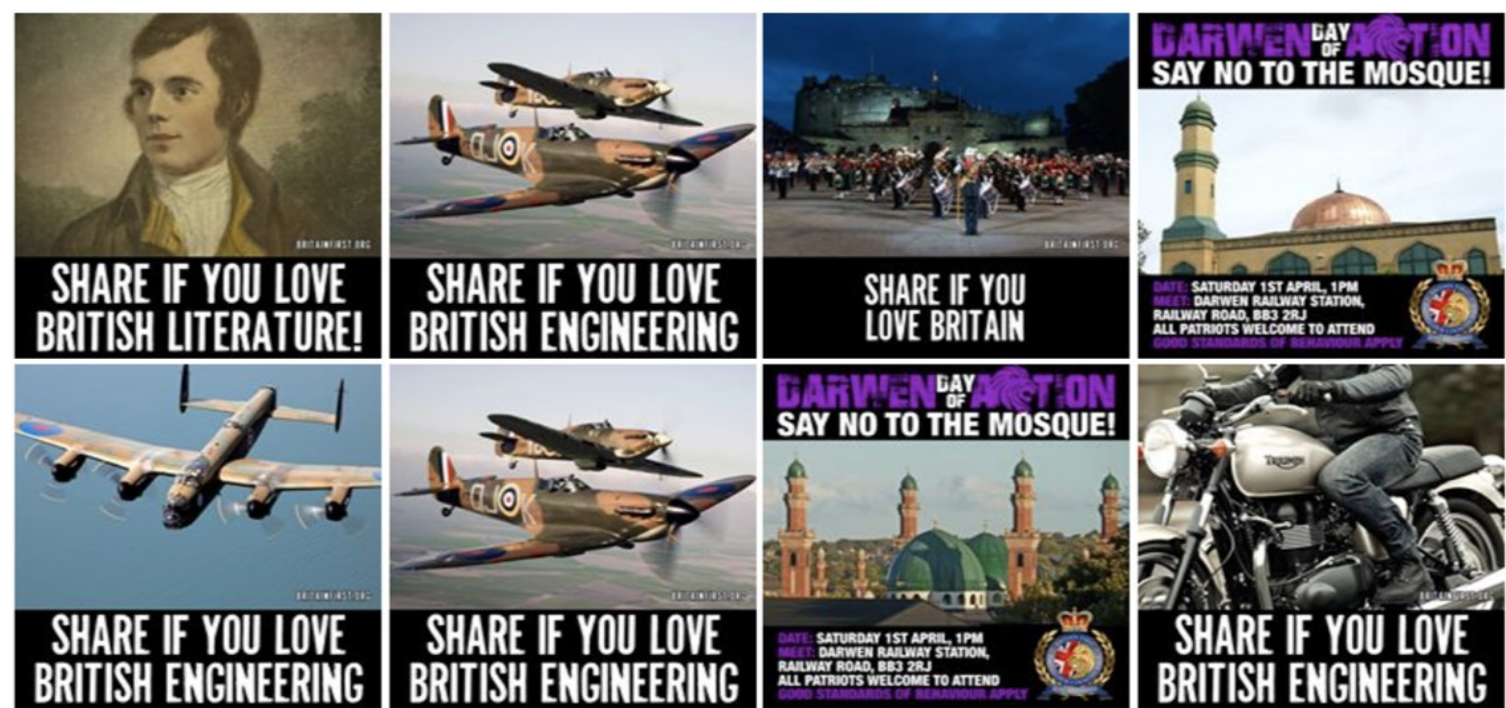

SHARE IF YOU LOVE
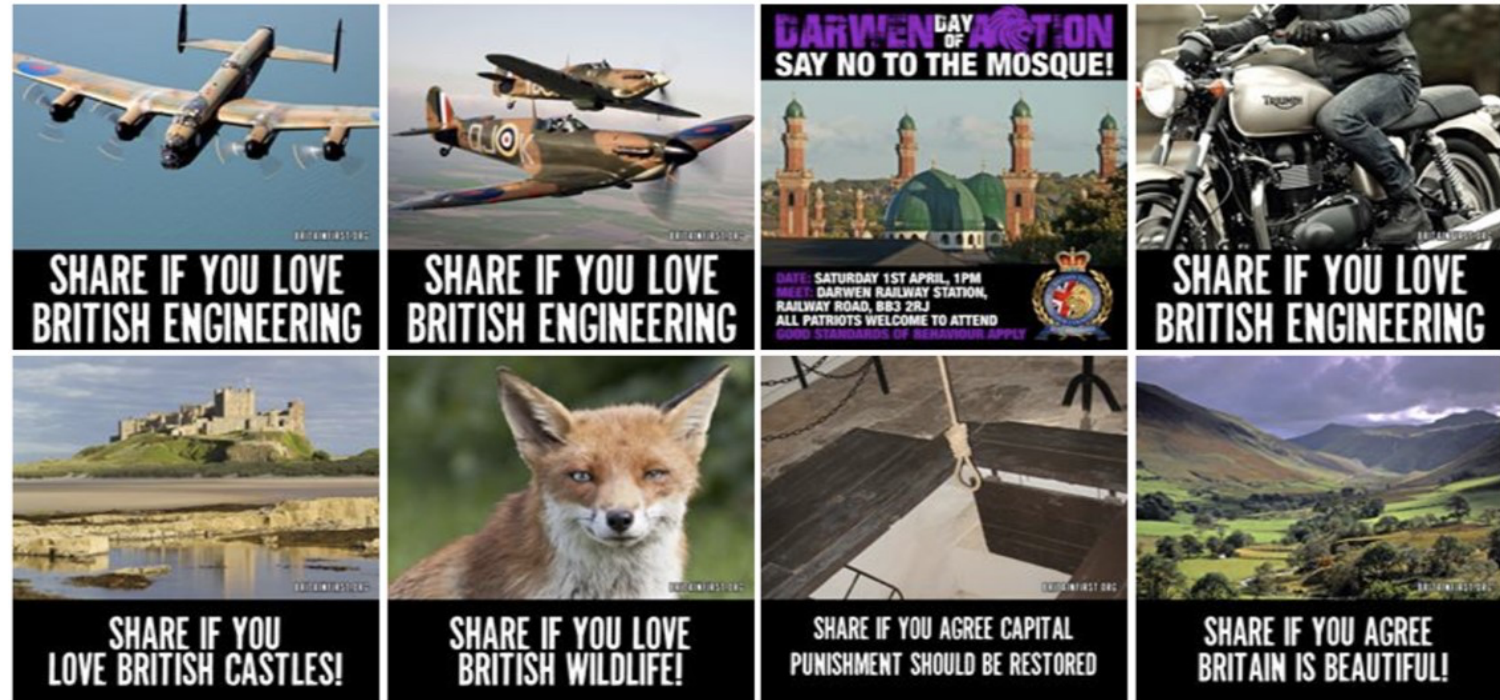

Note: Each thumbnail shows an image posted sequentially on the Britain First Facebook page. Many of the posts include text requesting users to "share" them. Screenshot by the author, 2017. 
Figure 3: Dependent variables in levels

Activity - Weekly posts by Britain First

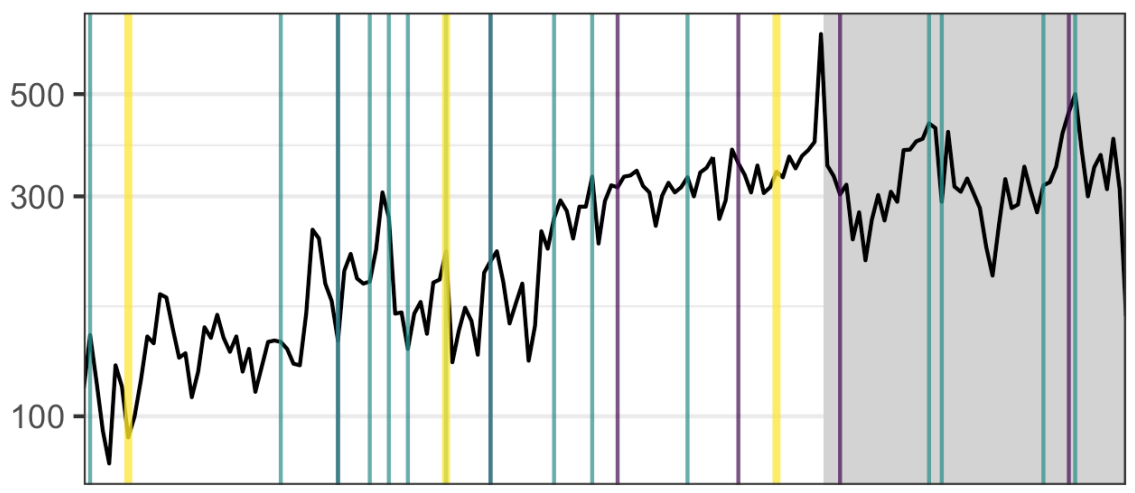

Recruitment - Weekly total new users

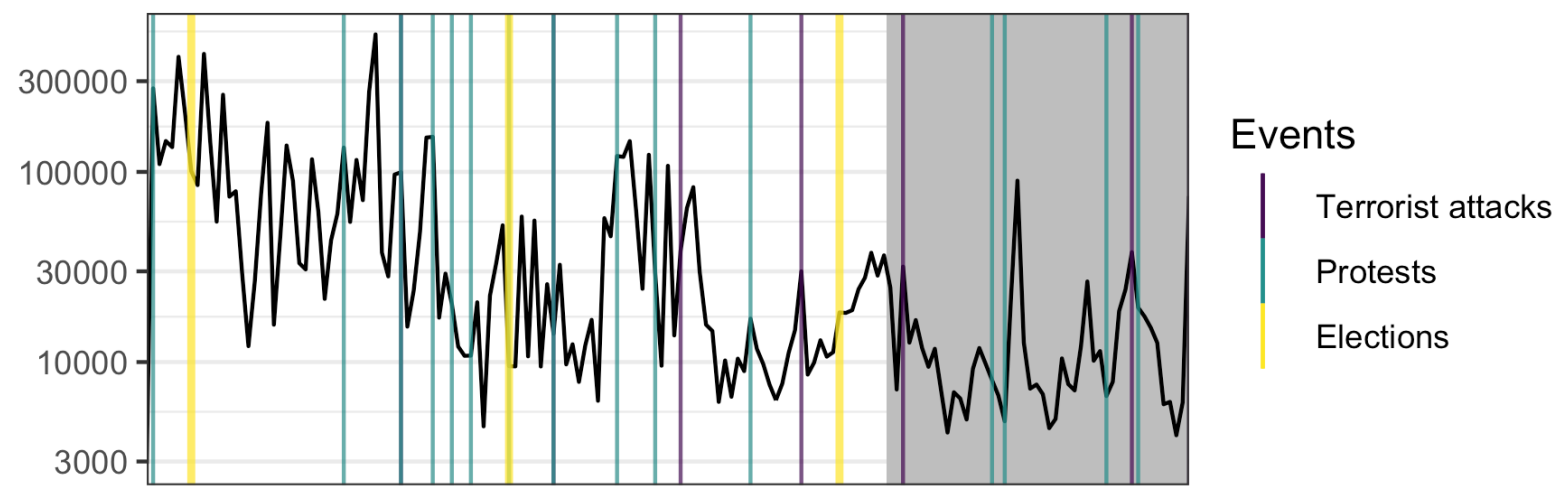

Support - Weekly average of daily active users

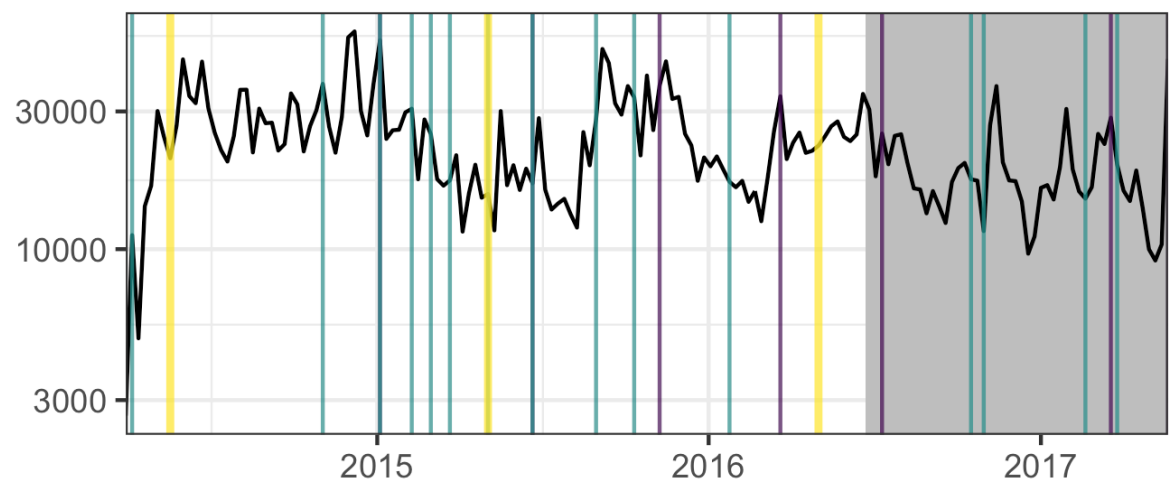

Note: The black line in each panel shows the weekly counts of each variable using a logarithm scale on the y-axis. Vertical lines indicate occurrence of events during the period. The gray shaded region denotes the period after the Brexit referendum. 
Figure 4: Dependent variables, log transformed first-differences

\section{Activity}

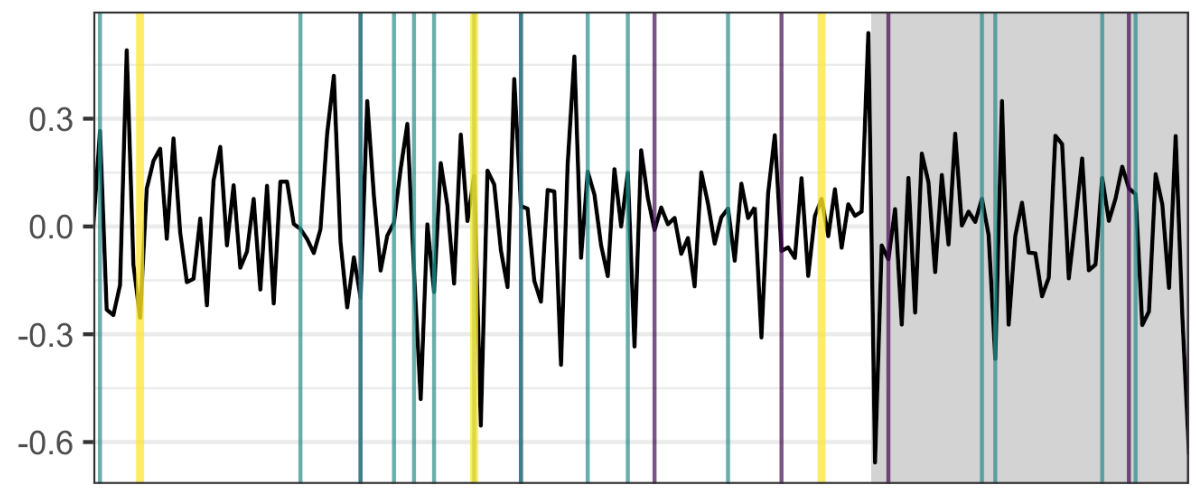

Recruitment

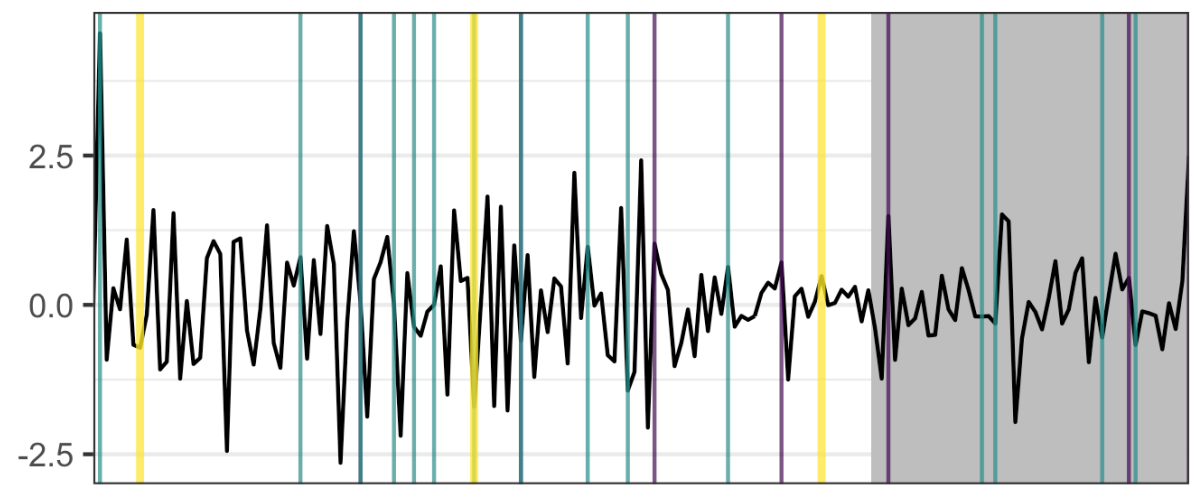

Events

Terrorist attacks

Protests

Elections

\section{Support}

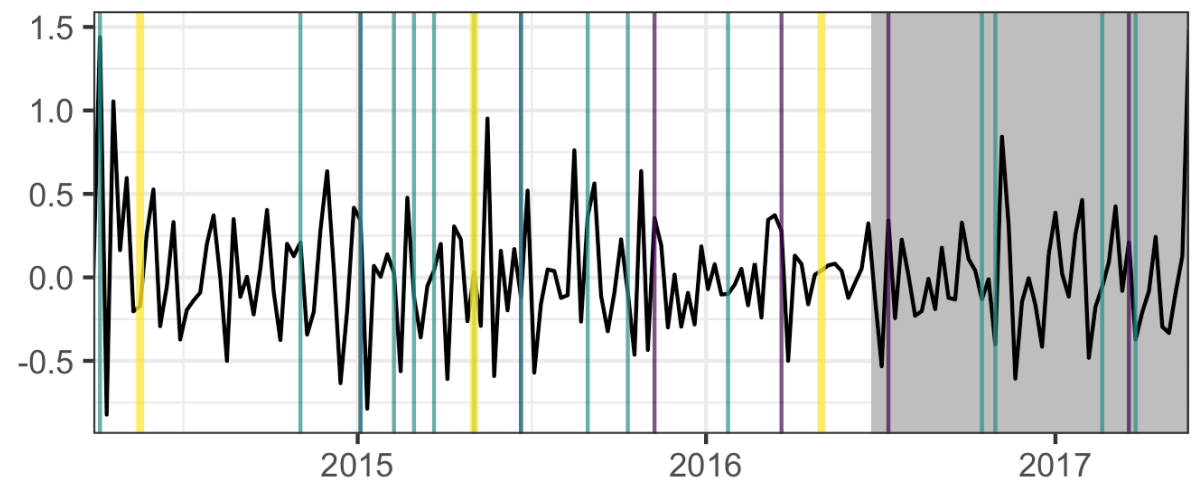

Note: The y-axis now shows the logarithm of the first-difference. The first week in each series set to zero as the first-difference is undefined. This observation is excluded from subsequent models. 
Figure 5: Simulated effect of shocks to key independent variables on BF activity
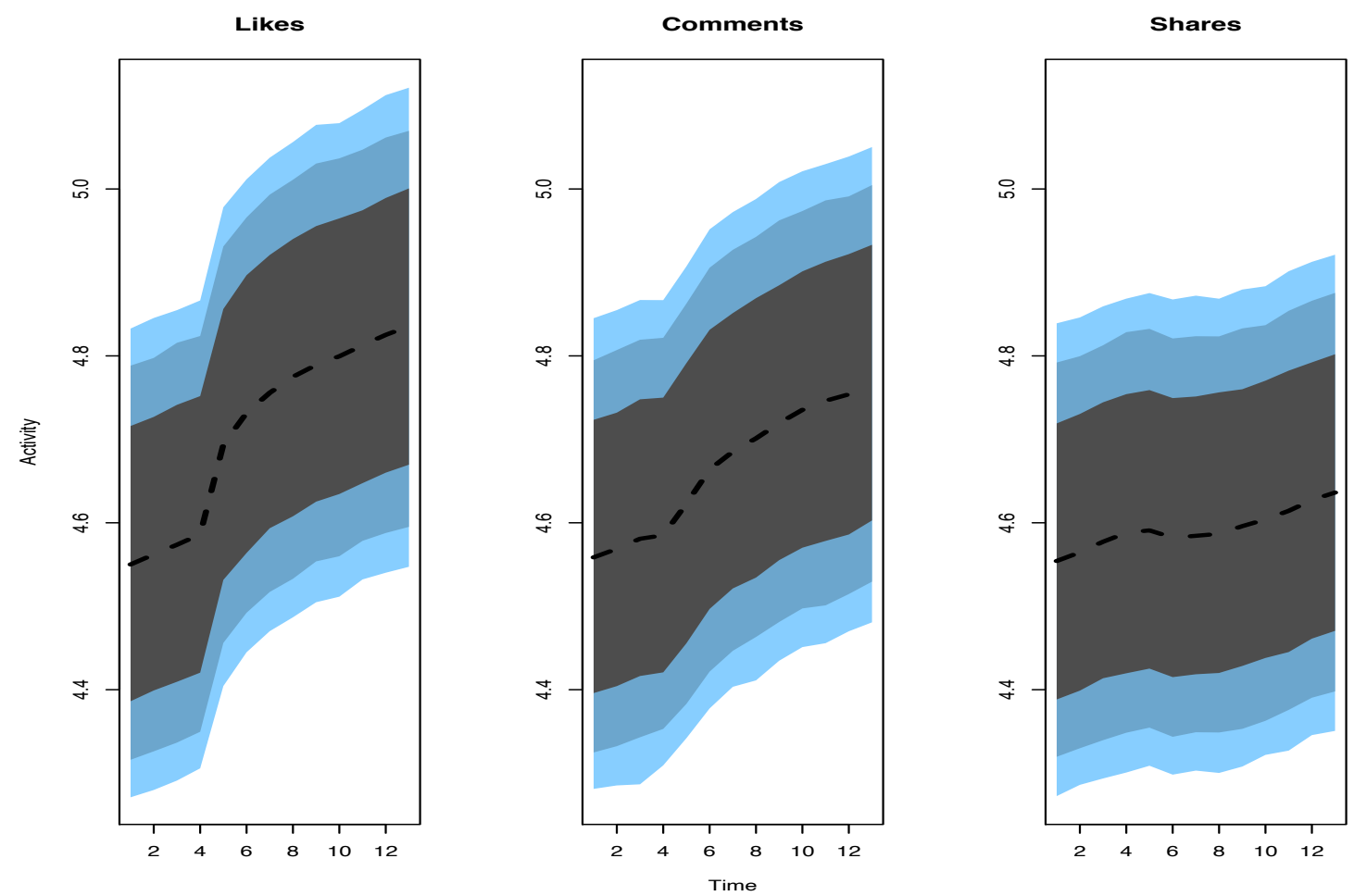

Note: The dashed lines in each panel indicate the mean value of the dependent variable over all simulations. The shaded regions indicate the lower and upper percentiles for the $75 \%, 90 \%$, and $95 \%$ density intervals, e.g., $75 \%$ of the estimates are within the dark gray region. 
Figure 6: Simulated effects of shocks to key independent variables on BF recruitment
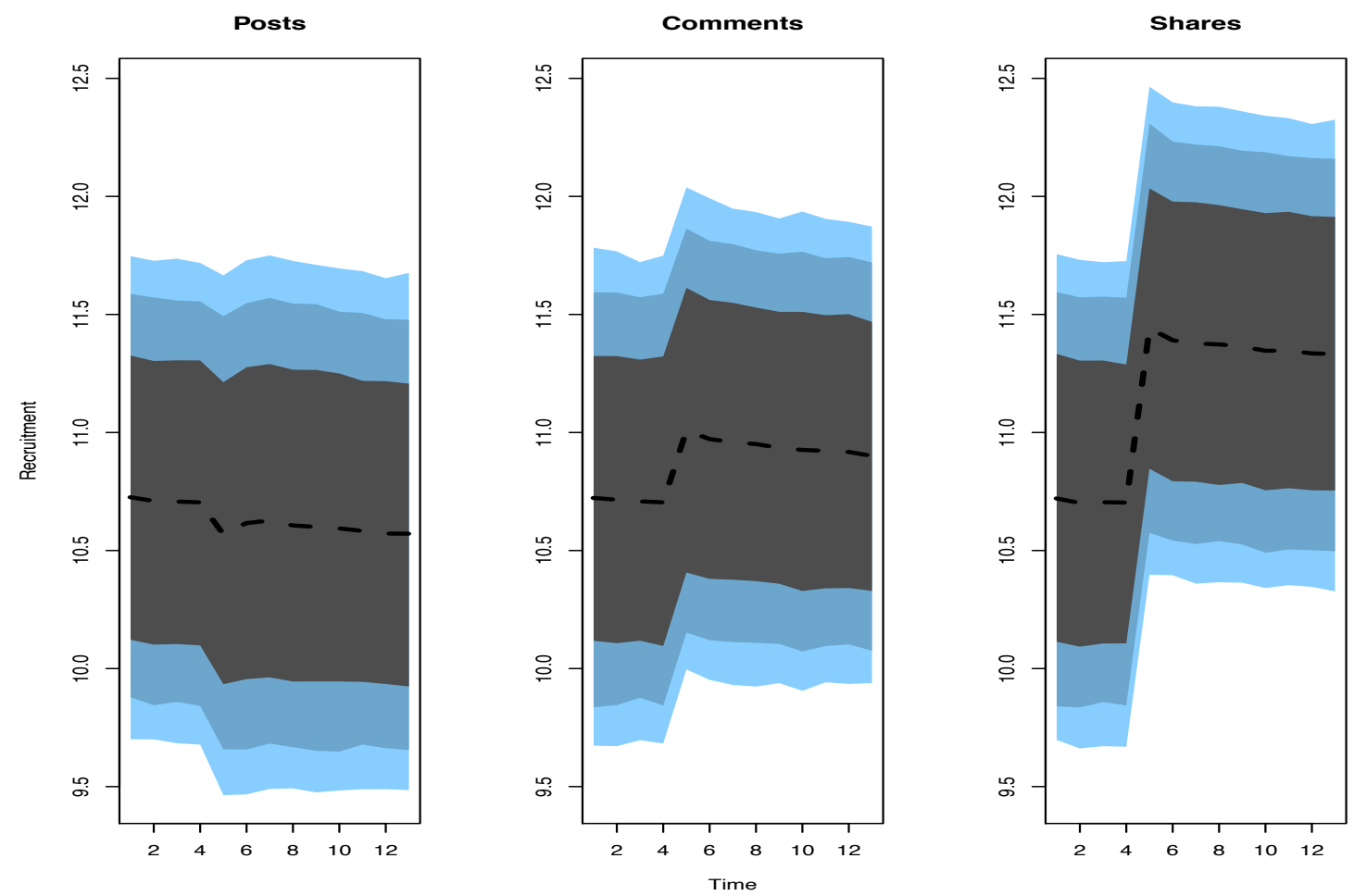

Figure 7: Simulated effects of shocks to key independent variables on BF support
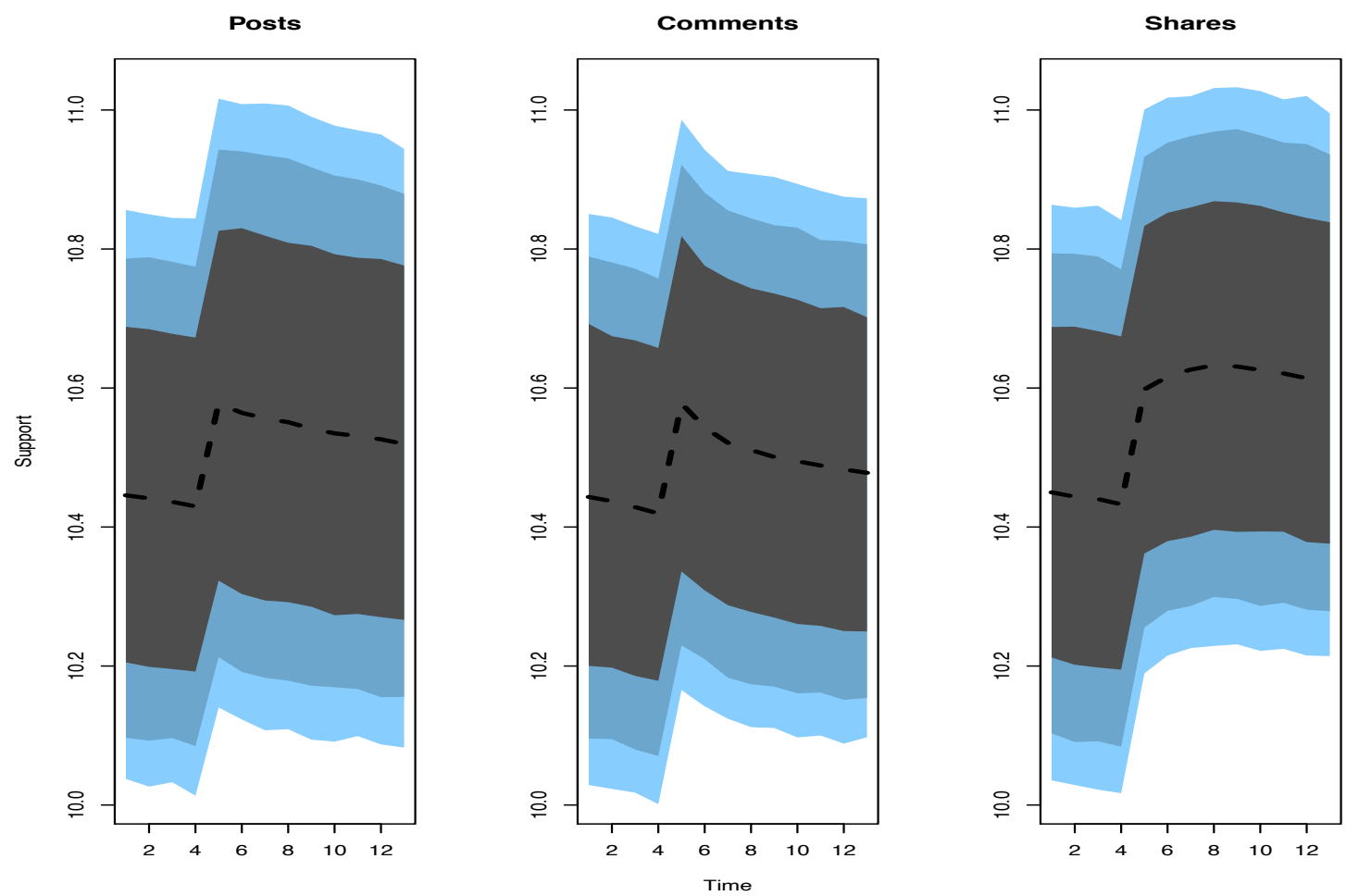
Figure 8: Simulated effects of shocks to key topic variables on BF recruitment
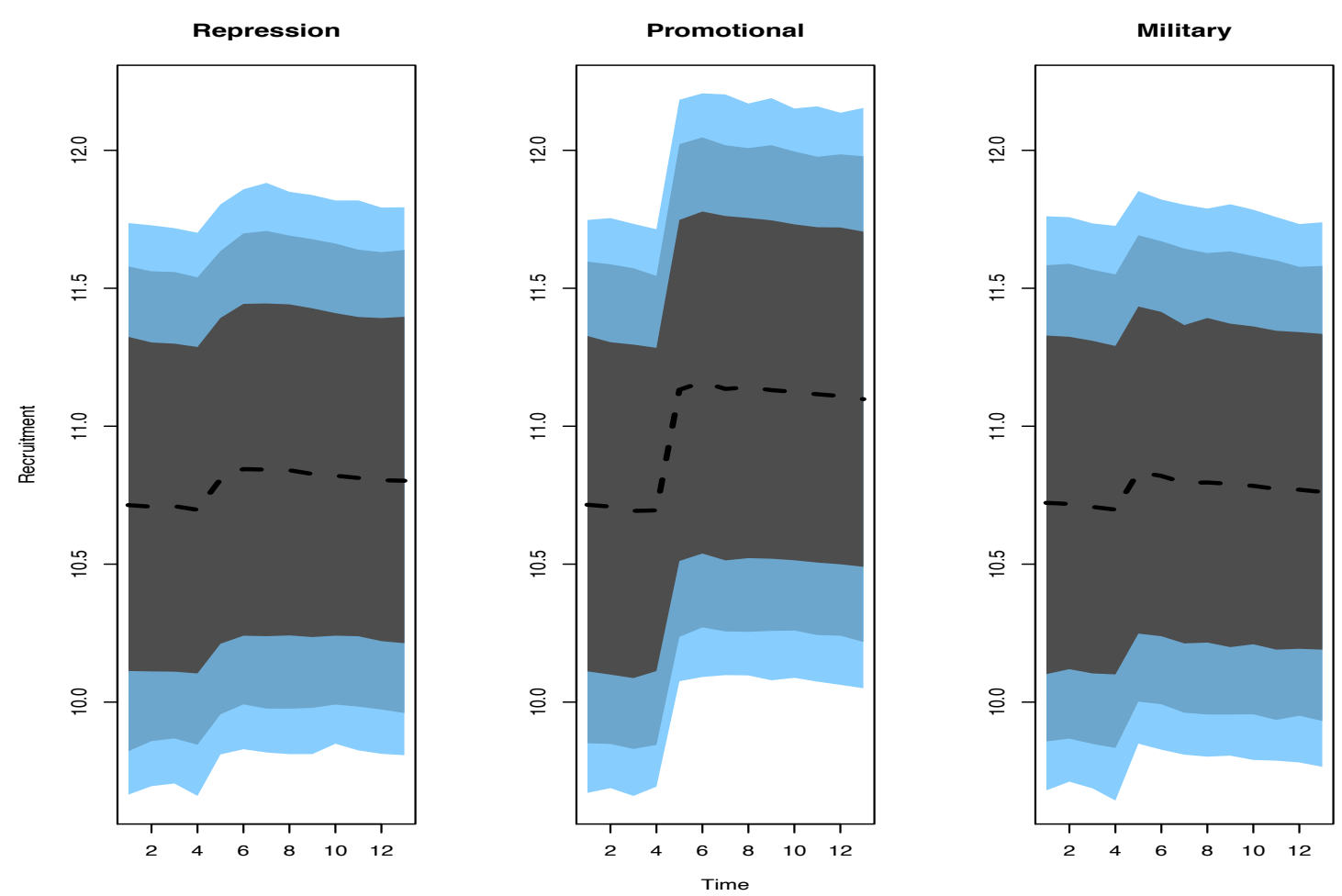
Figure 9: Simulated effect of key topic variables on support
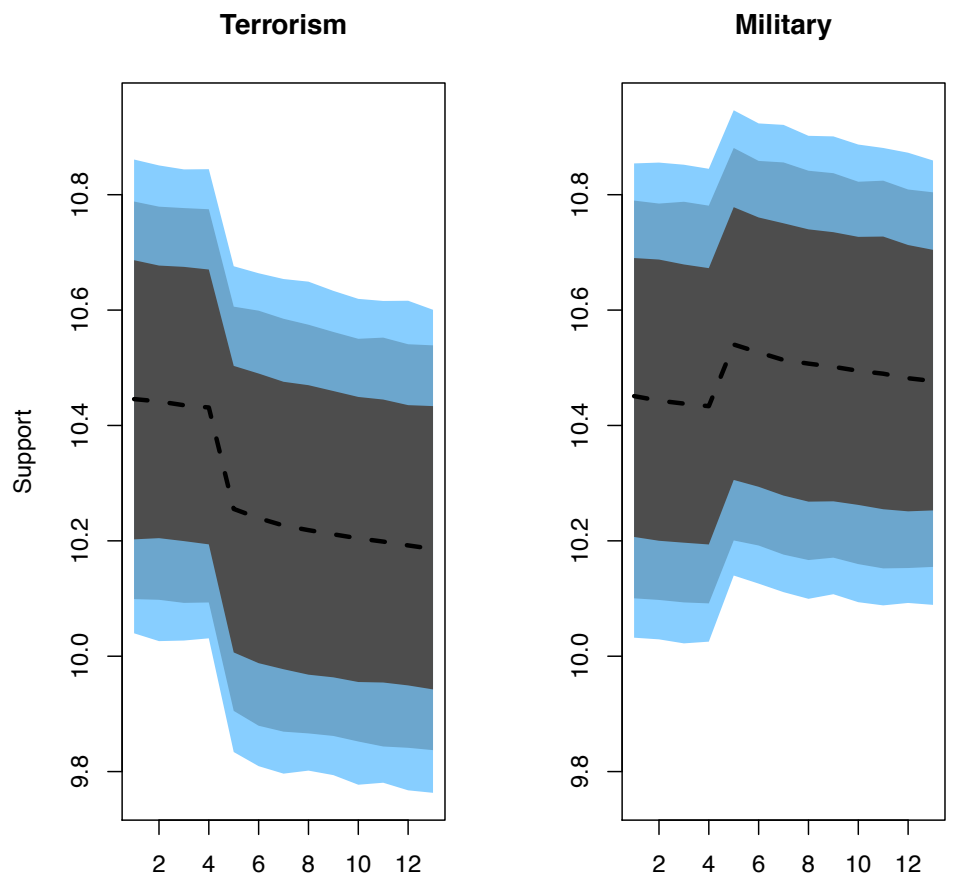
Figure 10: The system of cointegrating relationships

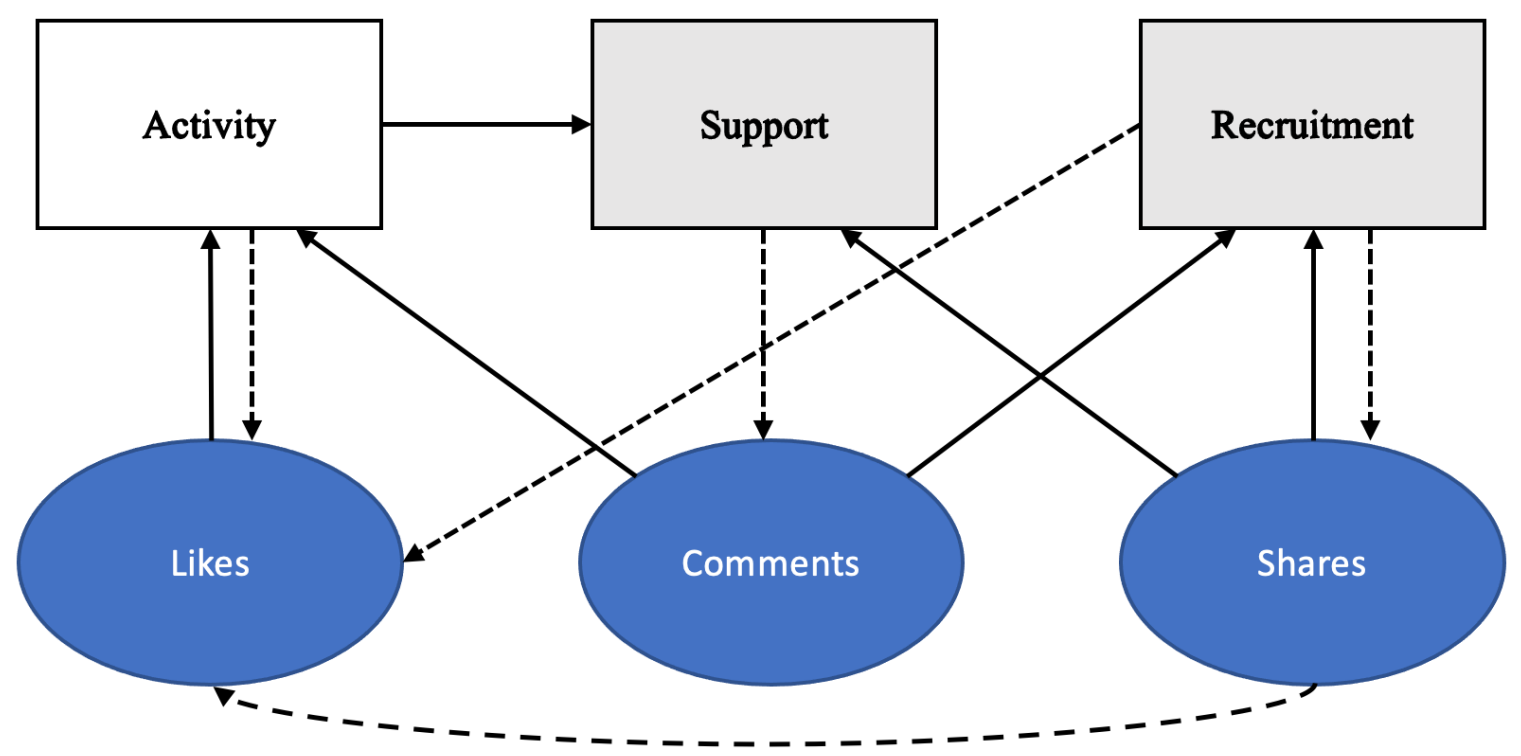

Note: This figure shows the observed relationships between each type of engagement and the three dependent variables. The solid black lines indicate cointegrating relationships based on statistically significant lagged coefficients in the main models. The dashed lines represent relationships observed in supplementary models estimating each type of engagement as a function of engagement and the three dependent variables. For example, the line from support to comments indicates that the lagged coefficient on support was statistically significant in the ECM predicting change in comments. Short-term relationships do not necessarily indicate cointegration and are therefore excluded from the diagram. Overall, this figure highlights the complex network of dynamic relationships between engagement and online mobilization. 


\section{TABLES}

\section{Table 1: Example posts from each (meta)topic}

\begin{tabular}{|c|c|c|c|}
\hline Topic type & Meta(topic) & $\widehat{\boldsymbol{\theta}_{k}}$ & Example(s) \\
\hline \multirow[t]{3}{*}{ Issue } & Crime & 0.029 & $\begin{array}{l}\text { "Armed police arrest man suspected of carrying knife outside } \\
\text { gates of UK parliament!" }\end{array}$ \\
\hline & Military & 0.029 & "The British armed forces are the best in the world!" \\
\hline & Islam & 0.165 & $\begin{array}{l}\text { "Pakistani mother handed death sentence for burning daughter } \\
\text { alive in "honor killing'?", "VIDEO: Muslims pray on the streets of } \\
\text { Rome", "BAN HALAL SLAUGHTER! Animals are hung upside- } \\
\text { down to bleed to death whilst conscious. Most Halal meat isn't } \\
\text { labelled!", "VIDEO: KFC MUSLIM EMPLOYEE SCREAMS } \\
\text { INSULTS AT CUSTOMER ASKING FOR BACON!" }\end{array}$ \\
\hline
\end{tabular}

Terrorism 0.094 'Jordan vows to 'wipe Isis out completely' as it investigates claim US hostage killed in air strike", "UK AIRPORTS, NUCLEAR PLANTS PLACED ON TERROR ALERT AS EXPERTS WARN OF 'CREDIBLE' SECURITY THREAT!", "Islamic extremists infiltrating schools, universities and scout groups"

Immigration 0.056 "Time to deport the lot of them and seal Europe's borders!", "INVASION! Fake refugees overrun Greek island"

Politics $\quad 0.072$ "Canada's Prime Minister is a treacherous leftwing snake!", "GO TRUMP: Donald Trump vows to stay in race amid calls to step down! ...", "... Britain First has nothing but contempt for the corrupt, media-rigged, phoney electoral system where the Old Gang parties of Lib-Lab-Con enjoy unchallenged supremacy ...", "PRESSURE IS BUILDING ON THE LABOUR PAEDOPHILE APOLOGISTS ..."

Instrumental Motivational0.042 "SO FAR WE HAVE OVERSEAS GUEST SPEAKERS CONFIRMED FROM POLAND, THE NETHERLANDS, THE 'PEGIDA' MOVEMENT, 'FORTRESS EUROPE' FROM GERMANY, FRANCE AND THE CZECH REPUBLIC, WITH MORE TO BE ANNOUNCED! ...", "Time to take our country back!"

Repression 0.065 "Sign the petition to DEMAND Twitter reinstates our profiles!", "TRIAL UPDATE Paul Golding is currently on trial at Chelmsford Magistrates Court. Prosecution are arguing their case."

Promotional 0.201 "DO YOU AGREE? SHARE and LIKE!", “...Leftwing Greenwich Council have refused to give hero Lee Rigby a memorial, despite giving one for Stephen Lawrence. Click below and complain! Template letter provided!... Please add "newsletter@ britainfirst.org" to your email contacts.", "Britain First issue advice to activists. Britain First", "The Taliban Hunting Club T-Shirt Available in Small - 4XL FREE UK DELIVERY ..."

Protests $\quad 0.047$ "JOIN US IN ROTHERHAM THIS SATURDAY 5TH SEPTEMBER! THERE ARE 1,400 REASONS WHY! ..."

Note: $\widehat{\theta_{k}}$ is the estimated proportion of each (meta)topic in the entire corpus. Examples are posts with high proportions of each topic. Metatopics include an example from each component topic. Some posts have been truncated for brevity, but original emphasis has been retained. 
Table 2: ECM predicting week change in number of posts by Britain First

\begin{tabular}{cc}
\hline $\mathrm{LDV}_{\mathrm{t}-1}$ & $-.464^{* * *, \alpha}$ \\
& $(.068)$
\end{tabular}

\section{Events}

Election $_{\mathrm{t}+1}$

$-.032$

$(.082)$

Election $_{\mathrm{t}}$

$-0.000$

$(.085)$

Election $_{\mathrm{t}-1}$

$-.181^{*}$

$(.085)$

Terrorist attack $\mathrm{t}_{\mathrm{H}}$

$-.075$

$(.060)$

Terrorist attack $\mathrm{t}_{\mathrm{t}-1}$

.075

(.061)

Protest $_{t+1}$

.075

$(.042)$

Protest $t_{t}$

.042

(.043)

Protest $t-1$

$-.002$

(.040)

Brexit $_{t+1}$

.366

(.230)

Brexit $t_{t}$

$.507^{*}$

(.224)

Brexit $_{t-1}$

$-.311$

(.157)

Post-Brexit

$-.152^{* *}$

(.050)

Differences

$\Delta$ Media $_{\mathrm{t}}$

$-.007^{*}$

(.003)

$.165^{* * *}$

$\Delta$ Likes t

.060

$(.045)$

$\Delta$ Shares ${ }_{\mathrm{t}}$

$-.005$

(.017)

Lags

Media t-1

$-.004$

(.004)

Likes $t-1$

$.123^{*}$

(.050)

Comments t-1

$.085^{*}$ 
Trend

Constant

\begin{tabular}{lc}
\hline Breusch-Godfrey & 0.79 \\
Shapiro-Wilk test & 0.975 \\
AIC & -67.047 \\
BIC & 7.203 \\
PSS F-test & $(2.33,3.46) 3.509$ \\
PSS t-test & $(-3.41,-5.29)-5.882$ \\
N & 163 \\
$\mathrm{R}^{2}$ & .530 \\
Adjusted R & .456 \\
Residual Std. Error & .138 \\
F Statistic & $7.170^{* * *}(\mathrm{df}=22 ; 140)$ \\
\hline
\end{tabular}

${ }^{*} \mathrm{p}<.05 ;{ }^{* *} \mathrm{p}<.01 ;{ }^{* * *} \mathrm{p}<.001 .{ }^{\alpha}$ indicates statistical significance with MacKinnon critical value for LDV (99\%). PSS test bounds in parentheses. 
Table 3: ECM predicting weekly change in new users liking Britain First's Facebook posts

\begin{tabular}{|c|c|c|}
\hline & (1) & (2) \\
\hline $\mathrm{LDV}_{\mathrm{t}-1}$ & $\begin{array}{c}-.729^{* * *}, \alpha \\
(.080)\end{array}$ & $\begin{array}{c}-.920^{* * *, \alpha} \\
(.096)\end{array}$ \\
\hline \multicolumn{3}{|l|}{ Events } \\
\hline Election $_{t+1}$ & $\begin{array}{c}.158 \\
(.267)\end{array}$ & $\begin{array}{c}.231 \\
(.272)\end{array}$ \\
\hline Election $_{\mathrm{t}}$ & $\begin{array}{c}.081 \\
(.275)\end{array}$ & $\begin{array}{c}.169 \\
(.299)\end{array}$ \\
\hline Election $_{\mathrm{t}-1}$ & $\begin{array}{l}-.089 \\
(.278)\end{array}$ & $\begin{array}{c}.042 \\
(.293)\end{array}$ \\
\hline Terrorist attack $_{\mathrm{t}}$ & $\begin{array}{c}.259 \\
(.196)\end{array}$ & $\begin{array}{c}.050 \\
(.209)\end{array}$ \\
\hline Terrorist attack $\mathrm{t}_{\mathrm{t}-1}$ & $\begin{array}{l}-.319 \\
(.198)\end{array}$ & $\begin{array}{l}-.241 \\
(.202)\end{array}$ \\
\hline Protest $_{t+1}$ & $\begin{array}{l}-.145 \\
(.133)\end{array}$ & $\begin{array}{l}-.254 \\
(.142)\end{array}$ \\
\hline Protest $_{t}$ & $\begin{array}{c}.215 \\
(.134)\end{array}$ & $\begin{array}{c}.188 \\
(.145)\end{array}$ \\
\hline Protest $t-1$ & $\begin{array}{c}.075 \\
(.130)\end{array}$ & $\begin{array}{c}.011 \\
(.137)\end{array}$ \\
\hline Brexit $t+1$ & $\begin{array}{l}-.759 \\
(.746)\end{array}$ & $\begin{array}{l}-.798 \\
(.753)\end{array}$ \\
\hline Brexit $_{t}$ & $\begin{array}{l}-.603 \\
(.748)\end{array}$ & $\begin{array}{c}.609 \\
(.811)\end{array}$ \\
\hline Brexit $_{t-1}$ & $\begin{array}{l}-.531 \\
(.515)\end{array}$ & $\begin{array}{l}-.757 \\
(.581)\end{array}$ \\
\hline Post-Brexit & $\begin{array}{l}.498^{* *} \\
(.166)\end{array}$ & $\begin{array}{c}.304 \\
(.201)\end{array}$ \\
\hline Differences & & \\
\hline$\Delta$ Media $_{\mathrm{t}}$ & $\begin{array}{c}.018 \\
(.011)\end{array}$ & $\begin{array}{c}.018 \\
(.011)\end{array}$ \\
\hline$\Delta$ Posts $\mathrm{t}$ & $\begin{array}{l}-.022 \\
(.254)\end{array}$ & $\begin{array}{l}-.305 \\
(.291)\end{array}$ \\
\hline$\Delta$ Comments $\mathrm{t}$ & $\begin{array}{l}.680^{* * *} \\
(.144)\end{array}$ & $\begin{array}{l}.703^{* * *} \\
(.171)\end{array}$ \\
\hline$\Delta$ Shares $_{\mathrm{t}}$ & $\begin{array}{l}.661^{* * *} \\
(.046)\end{array}$ & $\begin{array}{l}.674^{* * *} \\
(.047)\end{array}$ \\
\hline Lags & & \\
\hline Posts $t-1$ & $\begin{array}{c}.032 \\
(.230)\end{array}$ & $\begin{array}{l}-.134 \\
(.273)\end{array}$ \\
\hline Media $t-1$ & $\begin{array}{c}.023 \\
(.013)\end{array}$ & $\begin{array}{c}.023 \\
(.014)\end{array}$ \\
\hline
\end{tabular}


Comments $\mathrm{t}-1$

Shares t-1

Topic differences

$\Delta$ Motivational $\mathrm{t}$

.065

(.040)

$\Delta$ Repression $_{\mathrm{t}}$

.115

(.059)

$\Delta$ Promotional $_{\mathrm{t}}$

$.067^{*}$

(.028)

.018

(.037)

.047

(.033)

.044

(.045)

.021

(.076)

.017

(.075)

.063

(.109)

$.376^{*}$

(.170)

\section{Topic lags}

Motivational t-1

Repression $_{\mathrm{t}-1}$

Promotional $_{\mathrm{t}-1}$

Protests t-1

Islam t-1

Terrorism $\mathrm{t}-1$

Immigration $_{\mathrm{t}-1}$

Politics t-1

Crime t-1
$-.009$

(.039)

$.154^{*}$

(.063)

.066

(.035)

.009

(.041)

.067

(.039)

.019

(.052)

.042

(.088)

$-.002$

(.092)

$-.133$

(.128) 


\begin{tabular}{lcc} 
Military t-1 & & .317 \\
Trend & $-.009^{* *}$ & $(.217)$ \\
& $(.003)$ & -.007 \\
Constant & -.379 & $(.004)$ \\
& $(1.350)$ & -6.280 \\
\hline Breusch-Godfrey & 1.42 & $(3.730)$ \\
Shapiro-Wilk test & $0.98^{*}$ & 0.387 \\
AIC & 222.637 & 0.988 \\
BIC & 296.887 & 217.051 \\
PSS F-test & - & 353.176 \\
PSS t-test & - & $(2.33,3.46) 7.163$ \\
N & 163 & $(-3.41,-5.29)-9.59$ \\
$\mathrm{R}^{2}$ & .816 & 163 \\
Adjusted R & .787 & .861 \\
Residual Std. Error & .446 & .812 \\
F Statistic & $28.200^{* * *}(\mathrm{df}=22 ; 140)$ & .419 \\
\hline
\end{tabular}

${ }^{*} \mathrm{p}<.05 ;{ }^{* *} \mathrm{p}<.01 ;{ }^{* * *} \mathrm{p}<.001 .{ }^{\alpha}$ indicates statistical significance with MacKinnon critical value for LDV (99\%). PSS test bounds in parentheses. 
Table 4: ECM predicting weekly change in average daily active users liking Britain First's Facebook posts

\begin{tabular}{|c|c|c|}
\hline & (1) & (2) \\
\hline $\mathrm{LDV}_{\mathrm{t}-1}$ & $\begin{array}{c}-.465^{* * *, \alpha} \\
(.072)\end{array}$ & $\begin{array}{c}-.486^{* * *, \alpha} \\
(.082)\end{array}$ \\
\hline \multicolumn{3}{|l|}{ Events } \\
\hline Election $_{\mathrm{t}+1}$ & $\begin{array}{l}-.193 \\
(.109)\end{array}$ & $\begin{array}{l}-.216^{*} \\
(.107)\end{array}$ \\
\hline Election $_{\mathrm{t}}$ & $\begin{array}{c}.016 \\
(.114)\end{array}$ & $\begin{array}{c}.120 \\
(.120)\end{array}$ \\
\hline Election $_{\mathrm{t}-1}$ & $\begin{array}{l}-.040 \\
(.114)\end{array}$ & $\begin{array}{c}.026 \\
(.117)\end{array}$ \\
\hline Terrorist attack $\mathrm{t}$ & $\begin{array}{l}.179^{*} \\
(.080)\end{array}$ & $\begin{array}{l}.211^{*} \\
(.082)\end{array}$ \\
\hline Terrorist attack $\mathrm{t}_{\mathrm{t}-1}$ & $\begin{array}{l}-.149 \\
(.082)\end{array}$ & $\begin{array}{l}-.020 \\
(.082)\end{array}$ \\
\hline Protest $_{t+1}$ & $\begin{array}{l}-.049 \\
(.054)\end{array}$ & $\begin{array}{l}-.102 \\
(.057)\end{array}$ \\
\hline Protest $_{t}$ & $\begin{array}{c}.022 \\
(.055)\end{array}$ & $\begin{array}{c}.021 \\
(.059)\end{array}$ \\
\hline Protest $_{t-1}$ & $\begin{array}{l}-.020 \\
(.053)\end{array}$ & $\begin{array}{l}-.031 \\
(.055)\end{array}$ \\
\hline Brexit $_{t+1}$ & $\begin{array}{c}.091 \\
(.316)\end{array}$ & $\begin{array}{c}.008 \\
(.305)\end{array}$ \\
\hline Brexit $t_{t}$ & $\begin{array}{l}-.131 \\
(.304)\end{array}$ & $\begin{array}{l}-.095 \\
(.327)\end{array}$ \\
\hline Brexit $t-1$ & $\begin{array}{c}.056 \\
(.211)\end{array}$ & $\begin{array}{l}-.048 \\
(.231)\end{array}$ \\
\hline Post-Brexit & $\begin{array}{c}.065 \\
(.065)\end{array}$ & $\begin{array}{c}.158 \\
(.083)\end{array}$ \\
\hline Differences & & \\
\hline$\Delta$ Media $_{\mathrm{t}}$ & $\begin{array}{l}-.002 \\
(.005)\end{array}$ & $\begin{array}{c}.001 \\
(.005)\end{array}$ \\
\hline$\Delta$ Posts $_{\mathrm{t}}$ & $\begin{array}{l}.301^{* *} \\
(.105)\end{array}$ & $\begin{array}{l}.374^{* *} \\
(.115)\end{array}$ \\
\hline$\Delta$ Comments $_{\mathrm{t}}$ & $\begin{array}{l}.453^{* * *} \\
(.059)\end{array}$ & $\begin{array}{l}.355^{* * *} \\
(.067)\end{array}$ \\
\hline$\Delta$ Shares $_{\mathrm{t}}$ & $\begin{array}{l}.145^{* * *} \\
(.019)\end{array}$ & $\begin{array}{l}.153^{* * *} \\
(.019)\end{array}$ \\
\hline Lags & & \\
\hline Posts $t-1$ & $\begin{array}{c}.064 \\
(.098)\end{array}$ & $\begin{array}{c}.165 \\
(.110)\end{array}$ \\
\hline Media $t-1$ & .001 & .003 \\
\hline
\end{tabular}


$\begin{array}{lc} & (.005) \\ \text { Comments t-1 } & .218^{* * *} \\ \text { Shares } \mathrm{t}-1 & (.061) \\ & .065^{*} \\ \text { Topic differences } & (.025)\end{array}$

$\Delta$ Motivational $_{\mathrm{t}}$

$\Delta$ Repression $\mathrm{t}$

(.016)

.030

(.023)

$\Delta$ Promotional $_{\mathrm{t}}$

.003

(.011)

$\Delta$ Protests $_{\mathrm{t}}$

$-.006$

(.015)

0.000

$\Delta$ Islam $_{\mathrm{t}}$

(.013)

$\Delta$ Terrorism $_{\mathrm{t}}$

$-.044^{*}$

(.018)

$\Delta$ Immigration $\mathrm{t}$

(.030)

$\Delta$ Politics

.015

(.030)

$\Delta$ Crime $_{\mathrm{t}}$

.066

(.043)

$\Delta$ Military $_{\mathrm{t}}$

$.293^{* * *}$

(.068)

\section{Topic lags}

Motivational t-1

(.015)

Repression $_{\mathrm{t}-1}$

.011

(.023)

$-.006$

Promotional $_{\mathrm{t}-1}$

Protests $\mathrm{t}-1$

Islam t-1

Terrorism $\mathrm{t}-1$

$-.025$

(.020)

Immigration $_{\mathrm{t}-1}$

Politics t-1

Crime t-1

.026 


\begin{tabular}{lcc} 
Military t-1 & & $(.051)$ \\
& & .122 \\
Trend & -.001 & $.090)$ \\
& $(.001)$ & -.003 \\
Constant & $1.310^{*}$ & $(.002)$ \\
& $(.557)$ & 1.050 \\
\hline Breusch-Godfrey & 0.79 & $(1.380)$ \\
Shapiro-Wilk test & $0.975^{* *}$ & 0.901 \\
AIC & -67.047 & 0.989 \\
BIC & 7.203 & -82.051 \\
PSS F-test & - & 54.074 \\
PSS t-test & - & $(2.33,3.46) 3.271$ \\
N & 163 & $(-3.41,-5.29)-5.895$ \\
$\mathrm{R}^{2}$ & .750 & 163 \\
Adjusted R & .710 & .821 \\
Residual Std. Error & .183 & .759 \\
F Statistic & $19.100^{* * *}(\mathrm{df}=22 ; 140)$ & .167 \\
\hline
\end{tabular}

${ }^{*} \mathrm{p}<.05 ;{ }^{* *} \mathrm{p}<.01 ;{ }^{* * *} \mathrm{p}<.001 .{ }^{\alpha}$ indicates statistical significance with MacKinnon critical value for LDV (99\%). PSS test bounds in parentheses. 